\title{
Identifying and engineering the ideal microbial terpenoid production host
}

\author{
Sandra Moser ${ }^{1,2} \cdot$ Harald Pichler ${ }^{1,2}$ (1) \\ Received: 4 March 2019 / Revised: 3 May 2019 / Accepted: 6 May 2019 / Published online: 25 May 2019 \\ (C) The Author(s) 2019
}

\begin{abstract}
More than 70,000 different terpenoid structures are known so far; many of them offer highly interesting applications as pharmaceuticals, flavors and fragrances, or biofuels. Extraction of these compounds from their natural sources or chemical synthesis is - in many cases - technically challenging with low or moderate yields while wasting valuable resources. Microbial production of terpenoids offers a sustainable and environment-friendly alternative starting from simple carbon sources and, frequently, safeguards high product specificity. Here, we provide an overview on employing recombinant bacteria and yeasts for heterologous de novo production of terpenoids. Currently, Escherichia coli and Saccharomyces cerevisiae are the two best-established production hosts for terpenoids. An increasing number of studies have been successful in engineering alternative microorganisms for terpenoid biosynthesis, which we intend to highlight in this review. Moreover, we discuss the specific engineering challenges as well as recent advances for microbial production of different classes of terpenoids. Rationalizing the current stages of development for different terpenoid production hosts as well as future prospects shall provide a valuable decision basis for the selection and engineering of the cell factory(ies) for industrial production of terpenoid target molecules.
\end{abstract}

Keywords Yeast $\cdot$ Bacteria $\cdot$ Terpenoids $\cdot$ Microbial production hosts $\cdot$ Cell engineering $\cdot$ Metabolic engineering

\section{Introduction}

Terpenoids, i.e., terpenes and their functionalized derivatives, constitute one of the largest and structurally most diverse groups of natural compounds with over 70,000 different chemical structures (as listed in the Dictionary of Natural Products database (Vickers et al. 2017)). Although the majority of terpenoids have been found in plants, they also occur in insects (Laurent et al. 2003; Šobotník et al. 2010), in bacteria (Yamada et al. 2015), and in fungi (Quin et al. 2014). In accordance with their structural diversity, the functions of terpenoids range from mediating symbiotic or antagonistic interactions between organisms to electron transfer, protein prenylation, or contribution to membrane fluidity

Harald Pichler

harald.pichler@tugraz.at

1 Austrian Centre of Industrial Biotechnology (acib GmbH), Petersgasse 14, 8010 Graz, Austria

2 Institute of Molecular Biotechnology, NAWI Graz, BioTechMed Graz, Graz University of Technology, Petersgasse 14/2, 8010 Graz, Austria
(Gershenzon and Dudareva 2007; Wriessnegger and Pichler 2013; Pichersky and Raguso 2016). These properties render terpenoids highly interesting for various applications, such as pharmaceuticals, flavors and fragrances, biofuels and fuel additives, or in agriculture as pesticides (Wang et al. 2005; Zwenger and Basu 2008; Bohlmann and Keeling 2008; George et al. 2015). Many of these compounds are still extracted from their natural sources, in most cases plants, although this approach often suffers from seasonal and geographical variations in supply and quality. For example, low yields or even lack of sufficient plant material was demonstrated in the case of the potent anticancer drug Taxol (paclitaxel) that had been found in the bark of mature pacific yew trees. It was calculated that 2-3 million pacific yew trees would have to be sacrificed per year to cover the demand for cancer treatment in the USA only (Suffness 1995).

As an alternative supply route for many compounds, chemical synthesis has been established successfully (Jansen and Shenvi 2014). However, taking into account the progress made during the last two decades, biotechnological production of terpenoids now offers some major benefits. As recently analyzed for the example of $\mathrm{C}_{13}$-apocarotenoids (Cataldo et al. 2016), these advantages include renewable starting material, 
increased product specificity, mild process conditions, and the possibility to generate products considered natural. The latter feature is gaining importance especially in the fields of flavors and nutraceuticals. Microbial production hosts can start terpenoid biosynthesis from simple carbon sources due to endogenous metabolic pathways generating the universal precursors for all terpenoids, namely, isopentenyl diphosphate (IPP) and dimethylallyl diphosphate (DMAPP) (Fig. 1). The 2-C-methyl-D-erythritol-4-phosphate (MEP) pathway (also called DXP pathway) occurs in most bacteria as well as in plant chloroplasts and algae (Rohmer 1999) while the mevalonate (MVA) pathway is present in most eukaryotes, including plant cytosol, archaea, and eubacteria (Miziorko 2011). As shown in Fig. 1, condensation of two or more of the previously mentioned $\mathrm{C}_{5}$ molecules, IPP and DMAPP, leads to the formation of the larger prenyl diphosphate compounds farnesyl diphosphate (FPP), geranyl diphosphate (GPP), or geranylgeranyl diphosphate (GGPP) which represent the pool of precursors for terpenoid biosynthesis. Terpenoids are classified according to the number of carbon atoms they contain, starting from monoterpenoids $\left(\mathrm{C}_{10}\right)$, sesquiterpenoids $\left(\mathrm{C}_{15}\right)$, diterpenoids $\left(\mathrm{C}_{20}\right)$ to triterpenoids $\left(\mathrm{C}_{30}\right)$, and tetraterpenoids (carotenoids, $\mathrm{C}_{40}$ ) (Fig. 1). Additionally, a few special classes of terpenoids have been described such as hemiterpenoids $\left(\mathrm{C}_{5}\right)$ ( $\mathrm{Li}$ et al.
2018), sesterterpenoids $\left(\mathrm{C}_{25}\right)$ (Wang et al. 2013a), sesquarterpenoids $\left(\mathrm{C}_{35}\right)$ (Sato 2013), and polyterpenoids (> $\mathrm{C}_{40}$ ) (Swiezewska and Danikiewicz 2005) which will not be discussed in more detail within in this review.

\section{Metabolic engineering of microbial hosts for recombinant terpenoid production}

The MEP and the MVA pathways constitute the two main targets of cell engineering approaches aiming to enhance terpenoid productivity. To increase precursor levels, one possibility is to focus on key enzymes in precursor supply that might be flux-limiting. Examples for such enzymes include, amongst others, DXP synthase $(d x s)$ and isopentenyl diphosphate isomerase (idi) in the MEP pathway, which have been overexpressed in numerous studies of metabolic engineering of Escherichia coli (Albrecht et al. 1999; Kim and Keasling 2001; Leonard et al. 2010). Also in yeast, overexpression of either selected genes such as truncated HMG-CoA reductase 1 ( $\mathrm{t} H M G$ ) and FPP synthase (ERG20) (Ro et al. 2006; Shiba et al. 2007; Ignea et al. 2011) or even the whole MVA pathway (Westfall et al. 2012) significantly increased terpenoid yields. Another possibility to secure enhanced precursor supply is the

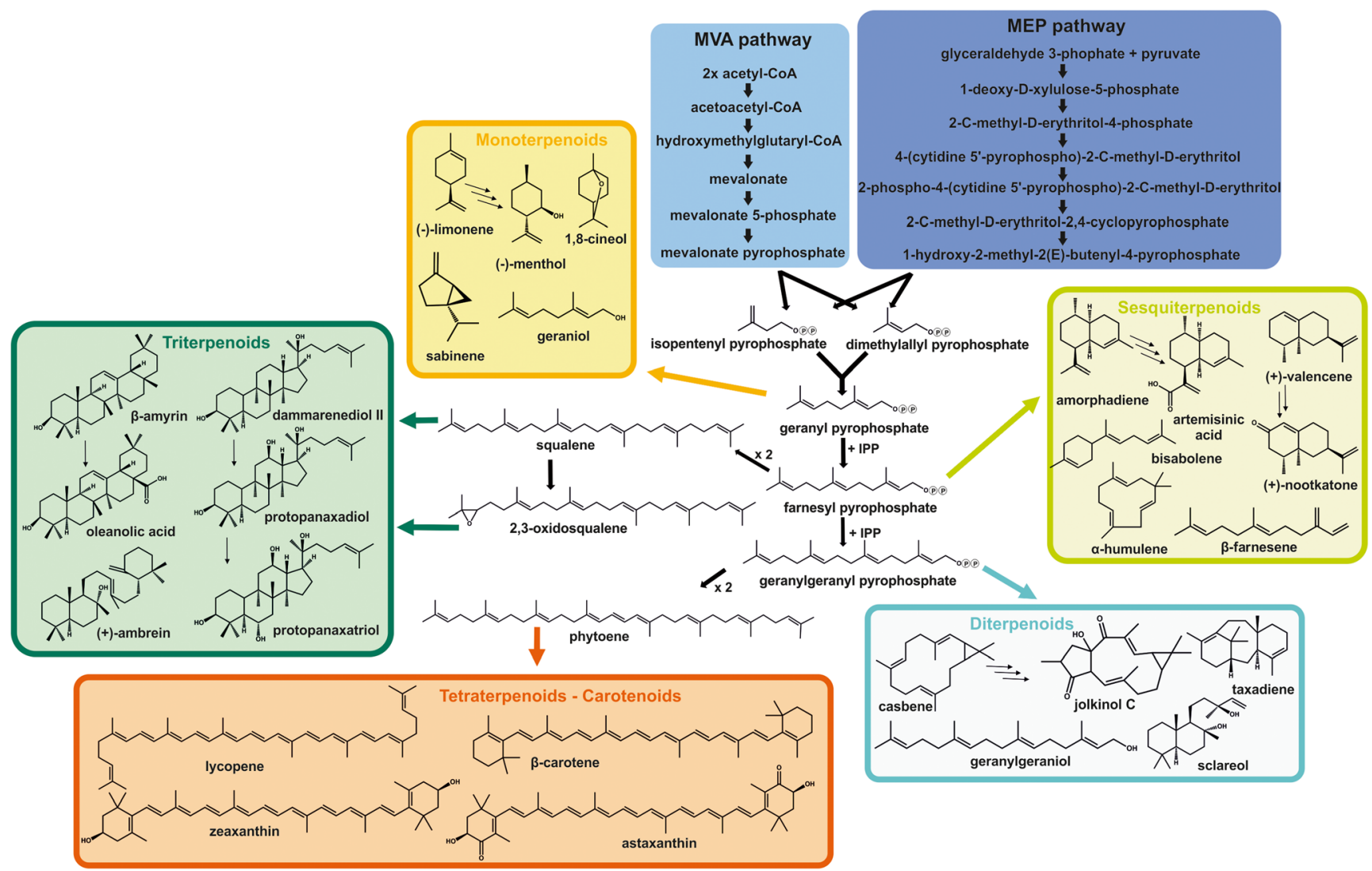

Fig. 1 Overview of precursor production for terpenoid biosynthesis starting with the mevalonate (MVA) pathway (most eukaryotes) or the 2-C-methyl-D-erythritol-4-phosphate (MEP) pathway (bacteria and plant chloroplasts) and examples for different terpenoid classes derived from these prenyl diphosphate precursors 
expression of heterologous pathway genes. Martin et al. (2003) integrated the MVA pathway of Saccharomyces cerevisiae into $E$. coli in addition to the native MEP pathway, which greatly enhanced supply of prenyl diphosphate molecules. It is hypothesized that this effect can be attributed to the lack of tight regulation of the heterologous pathway by the host cell (Martin et al. 2003). Several subsequent studies demonstrated the positive impact of heterologous pathway gene expression in E. coli on precursor production (Tabata and Hashimoto 2004; Tsuruta et al. 2009; Yoon et al. 2009; Zhao et al. 2011). In contrast, results for the opposite approach, namely, introduction of the MEP pathway of E. coli into yeast, have been far from being as successful. This is especially relevant since, when starting from glucose, the MEP pathway in $E$. coli has a theoretically higher carbon efficiency due to the carbon loss of acetyl-CoA formation for the MVA pathway. Moreover, efficiency of both pathways is also highly dependent of the selected carbon source (Gruchattka et al. 2013). Only recently, a functional substitution of the native MVA pathway by a heterologous MEP pathway has been achieved in S. cerevisiae. The last two enzymes of the MEP pathway, IspG and IspH, which contain iron-sulfur clusters and also require additional redox partners, seem to be the major bottlenecks as they cannot easily be expressed in soluble fashion in yeast (Kirby et al. 2016).

Strikingly, expression of heterologous MVA pathway genes turned out to be beneficial for yeast hosts in some cases, especially when the upper part of the pathway was targeted (Hansen 2011; Li et al. 2013; Peng et al. 2017). Particularly in yeast(s), it is essential to downregulate the endogenous ergosterol biosynthesis pathway, which is competing for precursors. A certain level of ergosterol is essential for cell viability and proliferation, though (Daum et al. 1998). Very often, this has been achieved by exchanging native promoters for weaker ones that are responsive to glucose (Scalcinati et al. 2012) or methionine (Asadollahi et al. 2008) levels in the cultivation medium or to intracellular ergosterol levels (Yuan and Ching 2015). Another possibility that has been described recently was to tag the competing enzyme for degradation. This strategy has been successful both for reducing squalene synthase levels by fusing it to a C-terminal peptide recognized by the endoplasmic reticulumassociated protein degradation mechanism in a sesquiterpenoidproducing yeast (Peng et al. 2017). In a similar approach aiming to improve a monoterpenoid-producing strain by targeting FPP synthase for degradation (Peng et al. 2018), an N-terminal degron was added to the enzyme. To ensure efficient channeling of prenyl precursors to heterologous terpenoid biosynthesis, bringing precursor pathway enzymes in close proximity to terpene synthases has been the strategy in several examples in the literature. Both attempts of direct fusion of enzymes (Albertsen et al. 2011; Wang et al. 2011; Zhou et al. 2012; Baadhe et al. 2013; Yang et al. 2016) and employing assembly domains (Zhao et al. 2016) have been beneficial in both E. coli and various yeast species as well as for various classes of terpenoids.

Particularly in yeasts - with only one pathway providing prenyl diphosphate precursors for terpenoid biosynthesisthe issue of acetyl-CoA supply for the mevalonate pathway has been addressed (reviewed recently in more detail also by Vickers et al. (2017)). A pyruvate dehydrogenase (PDH) bypass was engineered that by providing additional acetylCoA - through overexpression of native acetaldehyde dehydrogenase(s) together with a Salmonella enterica acetyl-CoA synthetase variant - clearly increased flux through the mevalonate pathway resulting in a further twofold increase in amorphadiene levels in the best strain available (Shiba et al. 2007). Based on this strategy, acetyl-CoA supply for terpenoid production was pushed even further by engineering a push-pull block strategy that enhanced production of the sesquiterpene $\alpha$-santalene fourfold. This increase in productivity was achieved by overexpressing a native alcohol dehydrogenase that converts ethanol to acetaldehyde and thereby channels it for additional acetyl-CoA supply (push). Furthermore, the first enzyme in the mevalonate pathway, acetyl-CoA C-acetyltransferase (pull), was overexpressed while reactions in the glyoxylate cycle competing for acetylCoA were inhibited (block) (Chen et al. 2013). A different approach, also aiming to improve overall acetyl-CoA supply, was to additionally utilize the mitochondrial acetyl-CoA pool by expressing the terpene synthase both in mitochondria and in the cytosol (Farhi et al. 2011). Engineering of central carbon metabolism for terpenoid biosynthesis was shifted to a new level by Meadows et al. (2016) who rendered S. cerevisiae more efficient in terms of ATP consumption and carbon flux. Endogenous pathways were replaced by heterologous metabolic reactions. For example, the previously described PDH bypass was substituted with an acetaldehyde dehydrogenase acylating (ADA) from Dickeya zeae which reduced the metabolic cost of farnesene by 18 ATPs, while expression of bacteria-derived xylulose-5-phosphate specific phosphoketolase and phosphotransacetylase circumvented $\mathrm{CO}_{2}$-emitting reactions. In addition, oxygen demand-of great importance for large-scale production -was decreased by astonishing $75 \%$. Combined, these engineering approaches resulted in $>130 \mathrm{~g} \mathrm{~L}^{-1}$ of $\beta$-farnesene, by far the highest value reported so far for recombinant terpenoid production (Meadows et al. 2016).

For more detailed information on host engineering, we refer the reader to several excellent reviews that focus either on specific hosts, especially E. coli (Li and Wang 2016; Ward et al. 2018) and S. cerevisiae (Paramasivan and Mutturi 2017; Vickers et al. 2017; Zhang et al. 2017) or on strain engineering for selected targets such as isoprene (Ye et al. 2016) mono- (Zebec et al. 2016) or diterpenoids (Kemper et al. 2017), lycopene (Ma et al. 2016a), or fragrance and flavor molecules (Carroll et al. 2016). 


\section{Alternative microbial hosts for terpenoid production}

To date, the majority of studies that aimed for microbial terpenoid production were based on E. coli or S. cerevisiae as production chassis. Accordingly, the highest terpenoid titers have been reported for these two hosts (Tsuruta et al. 2009; Westfall et al. 2012; Meadows et al. 2016). This preference can mainly be attributed to the extensive knowledge of genomics, genetic engineering, metabolism, and cell biology of these two microbes, which was available already two decades ago when metabolic engineering for terpenoid production was still in its infancy. In addition, also fast growth and relatively simple cultivation conditions are properties of high importance when selecting a host for production at industrial scale. Therefore, especially for bulk chemical production for which the efficient utilization of each supplied carbon atom is of high economic importance, these two organisms still remain to be the first choice for production of most terpenoid molecules. However, considering recent developments of genetic engineering tools for other microorganisms (reviewed by Cho et al. (2018) and Raschmanová et al. (2018)), potential advantages of alternative production hosts over the two model organisms gain momentum. Although current terpenoid titers in alternative hosts may still lack economic feasibility, future metabolic engineering approaches will benefit from already established large-scale production processes of other valuable compounds by various microorganisms such as amino acids from Corynebacterium glutamicum (Ikeda and Takeno 2013) or heterologous proteins secreted from Bacillus subtilis (Schallmey et al. 2004). To achieve economic and sustainable production, the utilization of cheap, preferably nonsugar/ nonfood carbon sources plays a major role. Substrates such as glycerol, ethanol, or methanol have been successfully employed for cultivation of Pichia pastoris, Yarrowia lipolytica, or Methylobacterium extorquens for terpenoid production (Matthäus et al. 2014; Wriessnegger et al. 2014; Sonntag et al. 2015; Czajka et al. 2018). Meanwhile, even lignocellulosic feedstocks become more amenable, although for most microorganisms, substantial cell engineering is necessary to achieve sufficient yields on this nutrient source (Wei et al. 2015a; Wendisch et al. 2016; Niehus et al. 2018).

Autotrophic bacteria, such as the cyanobacteria Synechococcus sp. and Synechocystis sp., Rhodobacter sphaeroides, or Cupriavidus necator, have been engineered for terpenoid production, in some cases actually utilizing $\mathrm{CO}_{2}$ as carbon source (Beekwilder et al. 2013; Choi et al. 2016; Formighieri and Melis 2017; Lee et al. 2017; Krieg et al. 2018). Photosynthetic bacteria are of specific interest as they are natural, high-level producers of terpenoids, more precisely pigments such as carotenoids, and therefore already operate the necessary metabolic pathways which can be further engineered to improve terpenoid yields (Pattanaik and
Lindberg 2015; Su et al. 2018). Another factor that may influence the choice of production host is the type of enzyme(s) required to obtain the target molecule(s). While many terpene synthases can be expressed solubly in diverse hosts, expression of cytochrome P450 enzymes (CYP450s) which functionalize terpenes and, thereby, contribute to the great diversity of terpenoids has been challenging in many cases (Renault et al. 2014). Most CYP450s of plant origin are membrane-anchored to the endoplasmic reticulum (ER). Accordingly, functional expression of these enzymes in bacteria often is poor compared with eukaryotic hosts. Furthermore, CYP450s require coexpression of CYP450 reductases (CPRs) also inserted into the ER membrane as reviewed by Renault et al. (2014). Yet, functional CYP450/ CPR coexpression in yeast(s) may bring along its issues as well, e.g., CPR instability, that may be cured by coexpression of ICE2 (Emmerstorfer et al. 2015). Another issue that should be considered when selecting a microbial chassis and that we discuss in the next section in more detail is the toxicity of intermediates or terminal products on the microbial hosts themselves, which can considerably lower the yields. Therefore, genetically amenable bacteria that, by nature, are more tolerant to solvents, such as Pseudomonas putida or B. subtilis (Sardessai and Bhosle 2002; Nielsen et al. 2009), might be advantageous for terpenoid production. Ultimately, aiming for commercial applications, the selection of an alternative host might allow more freedom to operate since engineering of terpenoid biosynthesis in E. coli or S. cerevisiae is already restricted due to broad patent claims.

In the following section, we survey the specific challenges of microbial de novo biosynthesis for each terpenoid class in more detail. We provide an overview on how far various microbial hosts have been developed to reach industrially feasible terpenoid titers (see also Fig. 2).

\section{Microbial production of different terpenoid classes}

\section{Monoterpenoids}

The precursor molecule of monoterpenoids, geranyl diphosphate (GPP), is formed by condensation of dimethylallyl diphosphate (DMAPP) and isopentenyl diphosphate (IPP) (Fig. 1). Only low levels of endogenous GPP can be detected in microorganisms as most of GPP is efficiently converted to farnesyl pyrophosphate (FPP) by condensation with another molecule of IPP (Anderson et al. 1989; Thulasiram and Poulter 2006). In order to ensure sufficient precursor supply for monoterpenoid biosynthesis in microbial hosts, two different approaches have proven to be successful. Expression of heterologous GPP synthases from plant yielded improved monoterpenoid levels in E. coli (Yang et al. 2013; Alonso- 


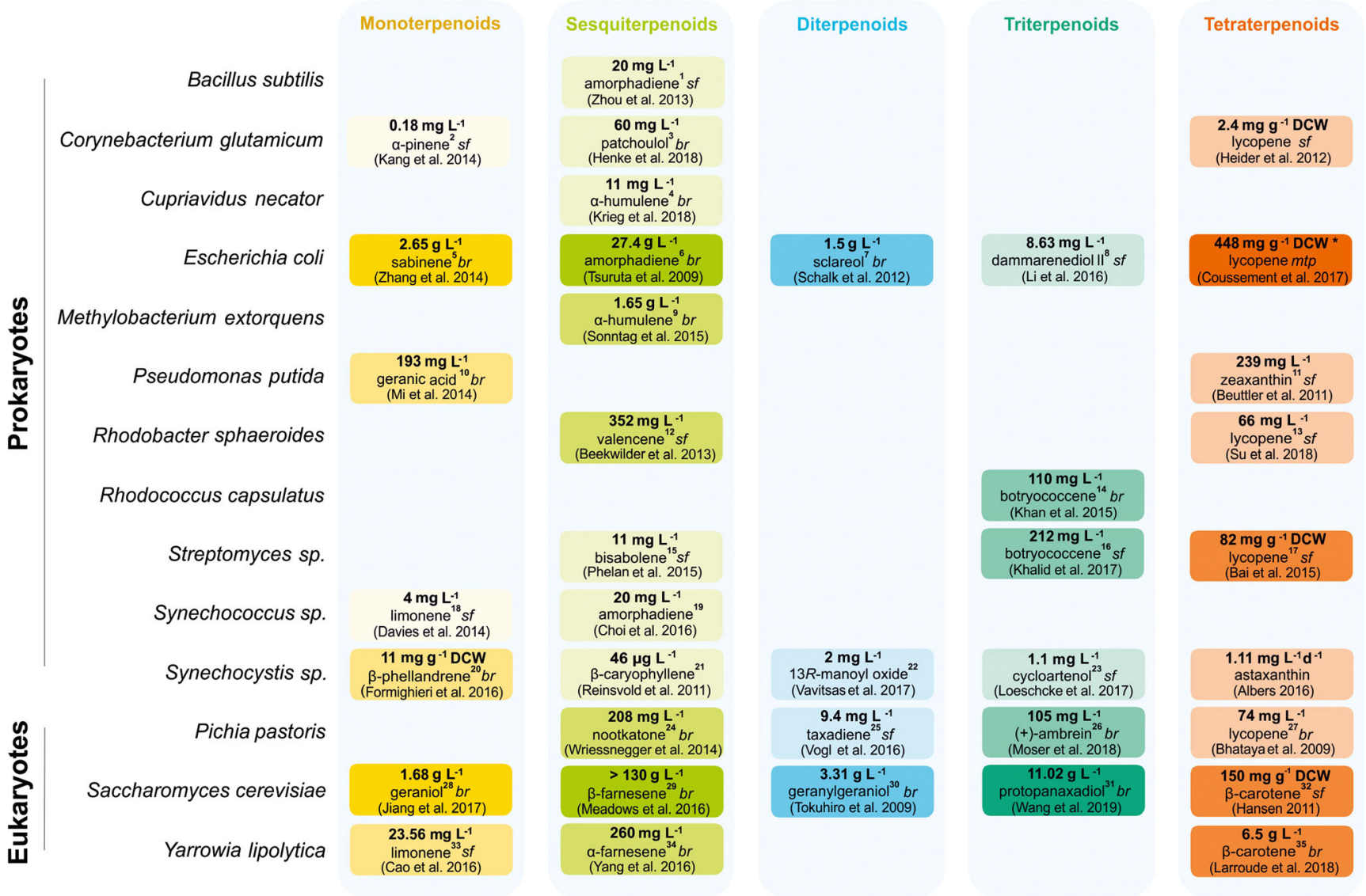

Fig. 2 Highest reported value for each terpenoid class produced by different microbial hosts. Color intensity correlates to produced amounts for each class. Mode of cultivation: shake flask (sf), bioreactor (br), microtiter plate (mtp). If no cultivation mode is stated, details were not elaborated in literature, or the values could not be clearly assigned to one of the three modes of cultivation. Since titers and yields cannot easily be correlated due to considerable variations in growth and cell densities of different species and engineered strains, values were taken as stated in literature, preferably as titer $\left(\mathrm{mg} \mathrm{L}^{-1}\right.$ or $\left.\mathrm{g} \mathrm{L}^{-1}\right)$, otherwise as space time yield ( $\mathrm{mg} \mathrm{L}^{-1} \mathrm{~d}^{-1}$ ) or specific yield ( $\mathrm{mg} \mathrm{g}^{-1}$ dry cell weight (DCW)). Superscript numbers behind the terpenoid molecule refer to footnotes with additional information on production time frame and eventually specific yield or space time yield, if available. Values that resulted from our own calculations based on available data in the respective study are given in italics. Asterisk indicates that this work has been substantially challenged by other authors (see Bian et al. 2018). ${ }^{1}$ Induction for 2 days; cultivation in $14 \mathrm{~mL}$ [sic!] Falcon tubes; ${ }^{2}$ induction for $52 \mathrm{~h}$; specific yield $20.4 \mu \mathrm{g} \mathrm{g}^{-1} \mathrm{DCW}{ }^{3}$ cultivation for $142 \mathrm{~h}$; maximum space time yield $18 \mathrm{mg} \mathrm{L}^{-1} \mathrm{~d}^{-1}$; specific yield $2 \mathrm{mg} \mathrm{g}^{-1} \mathrm{DCW} ;{ }^{4}$ cultivation for 7 days; specific yield $17 \mathrm{mg} \mathrm{g}^{-1} \mathrm{DCW}$; maximum space time yield $0.08 \mathrm{mg} \mathrm{L}^{-1} \mathrm{~h}^{-1} ;{ }^{5} 12 \mathrm{~h}$ of growth and $24 \mathrm{~h}$ of induction; maximum

Gutierrez et al. 2013; Zhang et al. 2014), S. cerevisiae (Ignea et al. 2011), P. putida (Mi et al. 2014), and C. glutamicum (Kang et al. 2014). Alternatively, the native FPP synthases of E. coli (Zhou et al. 2014) and S. cerevisiae (Fischer et al. 2011; Ignea et al. 2015) have been engineered to primarily yield GPP.

A major issue of microbial monoterpenoid production concerns the toxicity of these compounds to their production hosts. specific productivity $0.018 \mathrm{~g} \mathrm{~h}^{-1} \mathrm{~g}^{-1} \mathrm{DCW} ;{ }^{6}$ cultivation rounds lasted between 120 and $160 \mathrm{~h} ;{ }^{7}$ cultivation lasted close to 2 days including $20 \mathrm{~h}$ of induction; ${ }^{8}$ induction for $48 \mathrm{~h} ;{ }^{9}$ after $104 \mathrm{~h}$ of induction; average space time yield $14.6 \mathrm{mg} \mathrm{L}^{-1} \mathrm{~h}^{-1}$; specific yield $55 \mathrm{mg} \mathrm{g}^{-1} \mathrm{DCW}$; ${ }^{10}$ growth for $24 \mathrm{~h}$ and induction for $48 \mathrm{~h} ;{ }^{11} 48 \mathrm{~h}$ of induction; ${ }^{12}$ cultivation for $72 \mathrm{~h} ;{ }^{13}$ cultivation for $168 \mathrm{~h}$; specific yield $10.32 \mathrm{mg} \mathrm{g}^{-1} \mathrm{DCW}$; ${ }^{14}$ cultivation for $110 \mathrm{~h}$; specific yield $16.7 \mathrm{mg} \mathrm{g}^{-1} \mathrm{DCW} ;{ }^{15}$ cultivation for $72 \mathrm{~h} ;{ }^{16}$ cultivation for 9 days; ${ }^{17}$ cultivation for 5 days; ${ }^{18}$ cultivation for $96 \mathrm{~h}$; highest rate $50 \mu \mathrm{g} \mathrm{L}^{-1} \mathrm{~h}^{-1} ;{ }^{19}$ cultivation for 10 days; specific productivity over a $48 \mathrm{~h}$ culture $0.492 \mathrm{mg} \mathrm{L}^{-1} \mathrm{OD}_{730}{ }^{-1} ;{ }^{20}$ cultivation for $48 \mathrm{~h} ;{ }^{21}$ cultivation for 1 week; specific yield $3.7 \mu \mathrm{g} \mathrm{g}^{-1} \mathrm{DCW} ;{ }^{22} 2$ days of cultivation; specific yield $0.98 \mathrm{mg} \mathrm{g}^{-1} \mathrm{DCW} ;{ }^{23}$ specific yield $2.06 \mathrm{mg} \mathrm{g}^{-1} \mathrm{DCW}$; specific titer $0.92 \mathrm{mg} \mathrm{L}^{-1} \mathrm{OD}^{-1} ;{ }^{24}$ induction for $108 \mathrm{~h} ;{ }^{25}$ cultivation for $60 \mathrm{~h} ;{ }^{26}$ induction for $74 \mathrm{~h} ;{ }^{27}$ cultivation for $39.5 \mathrm{~h}$; specific yield $4.6 \mathrm{mg} \mathrm{g}^{-1} \mathrm{DCW} ;{ }^{28}$ after $130 \mathrm{~h}$ of cultivation; ${ }^{29}$ after 2 weeks; maximum space time yield $2.24 \mathrm{~g} \mathrm{~L}^{-1} \mathrm{~h}^{-1} ;{ }^{30} 206 \mathrm{~h}$ of cultivation; specific yield $70.9 \mathrm{mg} \mathrm{g}^{-1} \mathrm{DCW} ;{ }^{31} 144 \mathrm{~h}$ of fermentation; specific yield $76.9 \mathrm{mg} \mathrm{g}^{-1} \mathrm{DCW} ;{ }^{32}$ cultivation for $48 \mathrm{~h} ;{ }^{33}$ cultivation for 3 days; specific yield $1.36 \mathrm{mg} \mathrm{g}^{-1} \mathrm{DCW} ;{ }^{34}$ cultivation for $120 \mathrm{~h}$; specific yield $33.98 \mathrm{mg} \mathrm{g}^{-1}$ DCW; ${ }^{35}$ cultivation for $122 \mathrm{~h}$; specific yield $90 \mathrm{mg} \mathrm{g}^{-1}$ DCW

Apparent detrimental effects on membrane integrity have been described for different bacteria including $E$. coli as well as for S. cerevisiae (Sikkema et al. 1995; Trombetta et al. 2005). One possibility to overcome product toxicity is to perform biphasic cultivations for in situ extraction using dibutyl phthalate (Brennan et al. 2012), diisononyl phthalate (Willrodt et al. 2014), or dodecane (Alonso-Gutierrez et al. 2013) which also prevents loss of these highly volatile compounds. The same 
strategy is valid for cultures producing sesquiterpenoids. Another way is to heterologously express efflux pumps, a concept successfully implemented both in E. coli (Dunlop et al. 2011) and S. cerevisiae (Wang et al. 2013b). Recently, it has been demonstrated for $S$. cerevisiae that the toxic effect of limonene can primarily be attributed to disturbing cell wall integrity (Brennan et al. 2013). Accordingly, expression of a truncated form of tricalbin 3, a protein with possible involvement in cell wall integrity regulation, was found to be highly beneficial for increasing $S$. cerevisiae tolerance against limonene, $\beta$-pinene, and myrcene (Brennan et al. 2015). In E. coli, expression of a mutated alkyl hydroperoxidase reduced the accumulation of the spontaneous oxidation product of limonene, limonene hydroxide, which seems to constitute the actually toxic compound for microorganisms in the presence of limonene (Chubukov et al. 2016).

Currently, E. coli or S. cerevisiae constitute the most productive monoterpenoid hosts, with the reported titers being in the low $\mathrm{g} \mathrm{L}^{-1}$ range. Engineered E. coli yielded $2.65 \mathrm{~g} \mathrm{~L}^{-1}$ of the biofuel precursor sabinene (Zhang et al. 2014), $0.9 \mathrm{~g} \mathrm{~L}^{-1}$ of limonene (Willrodt et al. 2014), or $0.97 \mathrm{~g} \mathrm{~L}^{-1}$ of $\alpha$-pinene (Yang et al. 2013). Both Yang et al. (2013) and Zhang et al. (2014) employed an E. coli strain expressing a hybrid MVA pathway from Enterococcus faecalis and S. cerevisiae which was shown to be clearly superior to the native MEP pathway. The highest reported titers for S. cerevisiae were $1.68 \mathrm{~g} \mathrm{~L}^{-1}$ of geraniol after screening nine different synthases, improving expression thereof and fusing it to FPP synthase (Jiang et al. 2017) and $1.1 \mathrm{~g} \mathrm{~L}^{-1}$ of cineol by overexpressing, amongst others, a more stable variant of the HMGR isoenzyme HMG2 (K6R) as well as a chaperone (HSP90) (Ignea et al. 2011). Although levels are still markedly lower, some alternative hosts exhibit a significantly higher resistance to monoterpenoids, rendering them interesting production chassis for this terpenoid class. In particular, P. putida offers high tolerance to monoterpenoids (Speelmans et al. 1998), and engineered strains have been successfully applied for de novo production of geranic acid yielding $193 \mathrm{mg} \mathrm{L}^{-1}$ (Mi et al. 2014) as well as for conversion of 1,8-cineole (Mi et al. 2016) and limonene (Mirata et al. 2009). The study by Mi et al. (2014) underlined the potential advantage of $P$. putida as monoterpenoid producer as it exhibited a markedly higher resistance - by at least a factor of 6 - to geranic acid in comparison with both S. cerevisiae and E. coli (Mi et al. 2014). Also, the oleaginous yeast $Y$. lipolytica was engineered to produce $23.6 \mathrm{mg} \mathrm{L}^{-1}$ of limonene (Cao et al. 2016) and $7 \mathrm{mg} \mathrm{L}^{-1}$ of linalool (Cao et al. 2017). Other hosts that had been engineered for monoterpenoid production include cyanobacteria for the production of limonene (Davies et al. 2014) or $\beta$-phellandrene (Formighieri and Melis 2016) with the titers being in the low $\mathrm{m} \mathrm{L}^{-1}$ range. For the production of $\alpha$ - and $\beta$-pinene in $C$. glutamicum, product levels are still in the low, triple-digit $\mu \mathrm{g} \mathrm{L}^{-1}$ dimension (Kang et al. 2014).
In contrast to the above described biosynthesis of terpenoid backbones, further modifications of the hydrocarbons, as for example the conversion of limonene to menthol catalyzed by an enzyme cascade involving CYP450s from Mentha spp. (Turner and Croteau 2004), still remain a major challenge in microbial hosts. To our knowledge, no de novo biosynthesis of menthol from simple carbon source has been described, yet. However, a few approaches have been described that successfully produced menthol from pathway intermediates added externally (Toogood et al. 2015; Currin et al. 2018). Moreover, production and subsequent hydroxylation of limonene to another product, perillyl alcohol, in E. coli were reported to yield around $\sim 100 \mathrm{mg} \mathrm{L}^{-1}$ of functionalized monoterpene (Alonso-Gutierrez et al. 2013).

\section{Sesquiterpenoids}

To date, the most successful examples of microbial terpenoid production all fall into the class of sesquiterpenoids - which is not counterintuitive considering the essential nature of FPP-derived metabolites, e.g., sterols in eukaryotes. By far, the highest titers at $>130 \mathrm{~g} \mathrm{~L}^{-1}$ have been reported for production of $\beta$-farnesene - a building block for products ranging from cosmetics to fuel-using engineered $S$. cerevisiae. While synthesis of $\beta$-farnesene from FPP requires only a single enzyme, i.e., $\beta$-farnesene synthase, the major challenge was to modify carbon metabolism towards economic production of this bulk chemical by reducing ATP consumption and oxygen demand while improving carbon flux (Meadows et al. 2016), as discussed above. A far more complex biosynthetic route involving CYP450 activity and yielding in sufficient terpenoid for industrial scale was the production of precursors for artemisinin, an antimalarial drug. In S. cerevisiae, $>40 \mathrm{~g} \mathrm{~L}^{-1}$ of amorphadiene (Westfall et al. 2012) and $25 \mathrm{~g} \mathrm{~L}^{-1}$ of artemisinic acid (Paddon et al. 2013) that can be chemically converted to artemisinin were produced. In comparison with these values, the maximum titers reported for E. coli are $8.74 \mathrm{~g} \mathrm{~L}^{-1}$ of $\beta$-farnesene (You et al. 2017) and $27.4 \mathrm{~g} \mathrm{~L}^{-1}$ of amorphadiene (Tsuruta et al. 2009). Similarly, for two more sesquiterpenoids that can be produced in the low $\mathrm{g} \mathrm{L}^{-1}$ range, $S$. cerevisiae appears to be superior to $E$. coli at the moment. Bisabolene levels reached $5.2 \mathrm{~g} \mathrm{~L}^{-1}$ after screening of a yeast deletion collection (Özaydın et al. 2013) while a principal component analysis of proteomics (PCAP) study for E. coli resulted in $1.15 \mathrm{~g} \mathrm{~L}^{-1}$ of bisabolene (Alonso-Gutierrez et al. 2015). An early patent of Millis et al. (2001) described a $S$. cerevisiae strain capable of producing $4.95 \mathrm{~g} \mathrm{~L}^{-1}$ of farnesol while another study on isoprenoid alcohol production in E. coli reported farnesol levels of $1.4 \mathrm{~g} \mathrm{~L}^{-1}$ (Zada et al. 2018). In contrast, engineering of E. coli for production of $(-)-\alpha$-bisabolol and subsequent upscaling yielded $9.1 \mathrm{~g} \mathrm{~L}^{-1}$ which surpasses values reported for S. cerevisiae (Han et al. 2016). 
Partially, based on the extensive work done in the two bestestablished production hosts, engineering of a few other microorganisms has advanced far enough to achieve sesquiterpenoid production in 3-digit $\mathrm{mg} \mathrm{L}^{-1}$ range or higher. Sesquiterpenoid levels produced in such microbial hosts include for example $1.65 \mathrm{~g} \mathrm{~L}^{-1}$ of $\alpha$-humulene in M. extorquens, which is remarkable considering that this bacterium was, until then, mainly known as a model organism for methylotrophy and not as a production chassis (Sonntag et al. 2015). Another methylotrophic microorganism, the yeast $P$. pastoris, was successfully employed for the functional expression of a CYP450/CPR pair in addition to valencene synthase, resulting in $208 \mathrm{mg} \mathrm{L}^{-1}$ of the grapefruit flavor (+)-nootkatone (Wriessnegger et al. 2014). The oleaginous yeast $Y$. lipolytica was engineered to produce $260 \mathrm{mg} \mathrm{L}^{-1}$ of $\alpha$ farnesene by expressing a recombinant FPP synthase $/ \alpha$ farnesene synthase protein fusion in a strain modified for improved precursor production (Yang et al. 2016). Expression of a valencene synthase in a $R$. sphaeroides strain with a heterologous MVA pathway yielded $352 \mathrm{mg} \mathrm{L}^{-1}$ of valencene, a major aspect being the selection of a well-expressing synthase. In the same study, this synthase was also tested in a wild-type $S$. cerevisiae strain, but titers were considerably higher for the nonengineered bacterial host, thereby highlighting the potential of this phototrophic bacterium (Beekwilder et al. 2013). Also, a few other organisms were engineered for sesquiterpenoid biosynthesis such as C. glutamicum producing $60 \mathrm{mg} \mathrm{L}^{-1}$ of patchoulol (Henke et al. 2018), as well as $2.4 \mathrm{mg} \mathrm{L}^{-1}$ of valencene (Frohwitter et al. 2014) or B. subtilis yielding $20 \mathrm{mg} \mathrm{L}^{-1}$ of amorphadiene (Zhou et al. 2013). A $\beta$ caryophyllene synthase was introduced into the cyanobacterium Synechocystis sp. PCC6803 yielding $3.7 \mu \mathrm{g} \mathrm{g}^{-1}$ DCW (Reinsvold et al. 2011) while Streptomyces venezuelae was engineered to produce $10.5 \mathrm{mg} \mathrm{L}^{-1}$ of bisabolene (Phelan et al. 2015). In the latter study, also more complex carbon sources, such as cellobiose or ionic liquid-pretreated switchgrass, were successfully tested for bisabolene production, although titers were lower than with optimized medium. Further very interesting studies with regard to feedstock utilization were the production of $20 \mathrm{mg} \mathrm{L}^{-1}$ of amorphadiene (Choi et al. 2016) and $4.6 \mathrm{mg} \mathrm{L}^{-1}$ of $\alpha$-farnesene (Lee et al. 2017) by Synechococcus elongatus PCC 7942, and remarkable $17 \mathrm{mg} \mathrm{g}^{-1} \mathrm{DCW}$ of $\alpha$-humulene by $C$. necator (Krieg et al. 2018), using $\mathrm{CO}_{2}$ as sole carbon source in all cases.

Beyond artemisinic acid and (+)-nootkatone, also some further examples of de novo biosynthesis and subsequent functionalization of sesquiterpenes catalyzed by CYP450s have been described, although titers are still relatively low. $E$. coli has been engineered to produce $105 \mathrm{mg} \mathrm{L}^{-1}$ of 8hydroxycadinene (Chang et al. 2007) and-in a different study - an equivalent amount of costunolide which required heterologous expression of two CYP450s (Yin et al. 2015). $S$. cerevisiae was engineered to produce $50 \mathrm{mg} \mathrm{L}^{-1}$ of the dihydroxylated capsidiol (Takahashi et al. 2007) and, very recently, $40 \mathrm{mg} \mathrm{L}^{-1}$ of zerumbone which required biosynthesis of $\alpha$-humulene, subsequent hydroxylation catalyzed by a CYP450, and conversion by a zerumbone synthase variant (Zhang et al. 2018b).

Due to the extensive work done in the field of microbial sesquiterpenoid production within the last two decades, most of the terpenoids that are currently produced at commercial scale belong to this class. In addition to the already described high-level production of $\beta$-farnesene and artemisinic acid, also microbially produced flavor and fragrance molecules such as valencene or patchoulol are already on the market, as reviewed in more detail by Schempp et al. (2018).

\section{Diterpenoids}

Biosynthesis of diterpenoids starts from GGPP which is formed by condensation of FPP with IPP (Fig. 1). GGPP levels in microbial production hosts are too low under standard conditions and, thus, need to be boosted for recombinant diterpenoid production. Different strategies have been employed; therefore, $S$. cerevisiae possesses a native GGPP synthase, BTS1 (Jiang et al. 1995), that has been overexpressed either as single protein or as a part of fusion constructs with other pathway enzymes to enable efficient channeling of intermediates to push GGPP levels (Tokuhiro et al. 2009; Dai et al. 2012). Nevertheless, Bts1p catalytic activity is relatively low compared with GGPP synthases from other hosts (Ding et al. 2014). Therefore, in most studies engineering E. coli or S. cerevisiae for diterpenoid production, expression of heterologous GGPP synthases was the method of choice (Ajikumar et al. 2010; Morrone et al. 2010; Leonard et al. 2010; Dai et al. 2012; Schalk et al. 2012). Another possible solution was described by Ignea et al. (2015) who engineered the native FPP synthase of $S$. cerevisiae to a bifunctional enzyme that additionally produced significant amounts of GGPP. The benchmark for highest diterpenoid productivity is currently set by the production of $3.3 \mathrm{~g} \mathrm{~L}^{-1}$ (or $70.9 \mathrm{mg} \mathrm{g}^{-1} \mathrm{DCW}$ ) of geranylgeraniol which was achieved by creating fusion constructs of GGPP synthase with either FPP synthase or the endogenous diacylglycerol diphosphate phosphatase (Dpp1p) (Tokuhiro et al. 2009). A similar fusion approach was applied by Dai et al. (2012) for the generation of $488 \mathrm{mg} \mathrm{L}^{-1}$ of the tanshinone precursor miltiradiene, while Trikka et al. (2015) engineered S. cerevisiae for the production of $750 \mathrm{mg} \mathrm{L}^{-1}$ of the Ambrox precursor sclareol by knocking out six at first sight unrelated genes that had been identified in a carotenogenic screen. E. coli was employed to obtain $1.5 \mathrm{~g} \mathrm{~L}^{-1}$ of sclareol using two optimized synthases from Clary sage (Schalk et al. 2012). In the same host, $700 \mathrm{mg} \mathrm{L}^{-1}$ of levopimaradiene was reached through combinatorial mutagenesis of both GGPP and levopimaradiene synthase (Leonard et al. 2010). 
The most publicity for microbial diterpenoid biosynthesis was attracted by the production of precursors of Taxol, an anticancer drug whose natural synthesis from GGPP involves 19 steps (Jennewein et al. 2004). Biosynthesis of taxadiene, the first intermediate in Taxol biosynthesis reached $1 \mathrm{~g} \mathrm{~L}^{-1}$ in E. coli (Ajikumar et al. 2010), while for $S$. cerevisiae, the highest reported value is $8.7 \mathrm{mg} \mathrm{L}^{-1}$ (Engels et al. 2008). Accordingly, CYP450-mediated generation of oxygenated taxanes, the next intermediates en route to Taxol, was reported to yield $570 \mathrm{mg} \mathrm{L}^{-1}$ in E. coli (Biggs et al. 2016). The same intermediates could only be produced by $S$. cerevisiae in a cocultivation strategy with taxadiene-producing $E$. coli, yet the levels were still clearly lower at $33 \mathrm{mg} \mathrm{L}^{-1}$ (Zhou et al. 2015). In the same study, another functionalized diterpenoid was produced in a similar way by combining miltiradieneproducing $E$. coli with $S$. cerevisiae expressing a CYP450 required for subsequent conversion to ferruginol at $18 \mathrm{mg} \mathrm{L}^{-1}$. Very interesting with regard to cheap feedstock utilization was the recent engineering of $E$. coli for the production of $364 \mathrm{mg} \mathrm{L}^{-1}$ of taxadiene utilizing corn steep liquor and glycerol as carbon source (Hirte et al. 2018). On the other hand, $S$. cerevisiae has been engineered to produce about $800 \mathrm{mg} / \mathrm{L}$ of jolkinol $\mathrm{C}$ and a record $>1 \mathrm{~g} \mathrm{~L}^{-1}$ of oxidized casbanes that are potential intermediates for the synthesis of various pharmaceuticals (Wong et al. 2018). To our knowledge, the only examples for diterpenoid production in alternative hosts are the biosynthesis of $360 \mu \mathrm{g} \mathrm{g}^{-1} \mathrm{DCW}$ of geranyllinalool (Formighieri and Melis 2017) and $0.98 \mathrm{mg} \mathrm{g}^{-1}$ DCW of $13 R$-manoyl oxide (Vavitsas et al. 2017) in Synechocystis sp. PCC 6803 as well as the biosynthesis of $9.4 \mathrm{mg} \mathrm{L}^{-1}$ of taxadiene in P. pastoris (Vogl et al. 2016). Further analysis of the impact of these recombinant pathways and the resulting products on the cell as well as additional work on alleviating the bottleneck of GGPP supply will contribute to improving diterpenoid yields in alternative host.

\section{Triterpenoids}

Condensation of two FPP molecules leads to formation of squalene which can either be used directly or get epoxidized to 2,3-oxidosqualene for subsequent steps of triterpenoid production. The majority of currently known triterpenoids found in higher organisms are formed from 2,3-oxidosqualene while prokaryotes usually take squalene as starting compound for triterpenoid formation (Abe et al. 1993) Thus, yeasts naturally producing both squalene and 2,3-oxidosqualene for ergosterol biosynthesis have a major starting advantage over $E$. coli and other prokaryotes that require expression of heterologous squalene- and 2,3-oxiosqualene synthases. Accordingly, the highest titers of triterpenoids have been reported for S. cerevisiae. Dai et al. (2013) engineered S. cerevisiae for production of $1.55 \mathrm{~g} \mathrm{~L}^{-1}$ of the ginsenoside precursor dammarenediol II, and upon coexpression of a CYP450/ CPR pair, a remarkable amount of $1.19 \mathrm{~g} \mathrm{~L}^{-1}$ of protopanaxadiol was reported. Very recently, the production of dammarenediol II and subsequent conversion to protopanaxadiol was markedly improved through modular engineering of the MVA pathway combined with optimized CYP450 expression, finally yielding $11.02 \mathrm{~g} \mathrm{~L}^{-1}$ of protopanaxadiol (corresponding to $76.9 \mathrm{mg} \mathrm{g}^{-1} \mathrm{DCW}$ ) (Wang et al. 2019). Protopanaxadiol is converted to protopanaxatriol employing another CYP450 enzyme (Dai et al. 2014). Decoration of protopanaxadiol and protopanaxatriol through heterologous UDPglycosyltransferases in $S$. cerevisiae yielded natural (Wang et al. 2015, 2019; Wei et al. 2015b) or novel (Liang et al. 2017) bioactive compounds. The highest titer reported for de novo production of a fully functionalized and glycosylated ginsenoside so far is $2.25 \mathrm{~g} \mathrm{~L}^{-1}$ of the potential anticancer drug Rh2 in S. cerevisiae (Wang et al. 2019). Dammarenediol II production has also been described in $E$. coli, requiring introduction of heterologous 2,3oxidosqualene biosynthesis as well truncation of all $\mathrm{N}$ terminal transmembrane domains of involved enzymes ( $\mathrm{Li}$ et al. 2016) and P. pastoris (Zhao et al. 2016) but, in comparison with $S$. cerevisiae, at relatively low titers and specific yields of $8.63 \mathrm{mg} \mathrm{L}^{-1}$ and $1.04 \mathrm{mg} \mathrm{g}^{-1} \mathrm{DCW}$, respectively. $\alpha$ - and $\beta$-amyrin as well as their CYP450-derived products ursolic and oleanolic acid have been obtained in the low 3digit $\mathrm{mg} \mathrm{L}^{-1}$ range in $S$. cerevisiae (Lu et al. 2018). Recently, Zhao et al. (2018) enhanced oleanolic acid levels to $607 \mathrm{mg} \mathrm{L}^{-1}$ in $S$. cerevisiae. In addition to pushing precursor supply, the pairing of CYP450/CPR was optimized, and the galactose regulatory network was targeted to avoid negative effects on heterologous protein expression under the control of the ubiquitously used GAL promoter in the presence of glucose, which in addition also eliminated the requirement for cost-intensive supplementation with high amounts of galactose (Zhao et al. 2018). A very interesting approach with regard to overcoming the bottleneck of heterologous CYP450 expression in $S$. cerevisiae was described by Arendt et al. (2017) by engineering a yeast cell with significantly expanded endoplasmic reticulum to accommodate several, plant-derived CYP450 enzymes. This resulted in a 16-fold increase in production levels of medicagenic-28-O-glucoside, an oxidized and subsequently glycosylated derivative of $\beta$-amyrin (Arendt et al. 2017).

In contrast to $E$. coli, which is currently no competition for $S$. cerevisiae in triterpenoid production, the potential of several other hosts has been demonstrated in recent years. Our laboratory has recently reported the engineering of methylotrophic yeast $P$. pastoris for the biosynthesis of the squalene-derived (+)-ambrein, yielding $105 \mathrm{mg} \mathrm{L}^{-1}$ (Moser et al. 2018). Other hosts were modified to produce botryococcene in a similar range, such as Streptomyces 
reveromyceticus $\mathrm{SN}-593$, a strain with a native mevalonate operon, that upon fine-tuning of expression of its global regulator of terpenoid biosynthesis, Fur22, yielded $212 \mathrm{mg} \mathrm{L}^{-1}$ (Khalid et al. 2017). Rhodobacter capsulatus produced $110 \mathrm{mg} \mathrm{L}^{-1}$ of botryococcene in an autotrophic cultivation setup supplying only $\mathrm{CO}_{2}, \mathrm{H}_{2}$, and $\mathrm{O}_{2}$ that yielded almost threefold more in titer compared with a glucose-based fed batch (Khan et al. 2015). The first synthesis of triterpenoids derived from 2,3-oxidosqualene in cyanobacteria was described by Loeschcke et al. (2017) who engineered Synechocystis sp. PCC 6803 for the production of cycloartenol, lupeol, and marneral. Additionally, traces of hydroxylated derivatives of lupeol and marneral were detected, presumably due to endogenous CYP450 activity.

\section{Tetraterpenoids (carotenoids)}

Contrary to the terpenoid classes described above, for which most terpene synthases were derived from plants, carotenoid biosynthetic genes can also be found in many prokaryotes, fungi, or archaea (Sandmann 2002). This might constitute a possible advantage when heterologously overexpressing these biosynthetic genes in microbial production hosts. This hypothesis is supported by the fact that most studies in this section describing successful carotenoid production employed genes derived from microorganisms, fungi, or algae (Hansen 2011; Nam et al. 2013; Chen et al. 2016; Larroude et al. 2018). Upon condensation of two GGPP molecules, phytoene, the precursor for all carotenoids, is formed (Fig. 1). In noncarotenogenic hosts, this step requires heterologous expression of a phytoene synthase. In contrast to the other terpenoid classes, for which $E$. coli and $S$. cerevisiae are undisputedly the leading production hosts, the oleaginous yeast $Y$. lipolytica has been engineered to reach similar or even higher yields of different carotenoids. One major advantage of Y. lipolytica is its capability to form large lipid bodies in which high amounts of hydrophobic compounds, including carotenoids, can be stored (Matthäus et al. 2014). This ability can be further exploited upon strain engineering. For example, its native, already high acetyl-CoA flux can be engineered which renders $Y$. lipolytica, a highly promising host platform for terpenoid and lipid biosynthesis (Tai and Stephanopoulos 2013). Reported $\beta$-carotene yields are highest at $150 \mathrm{mg} \mathrm{g}^{-1}$ DCW for a $S$. cerevisiae strain that expressed a heterologous mevalonate pathway; each gene of which was selected from a different source, together with an ATP citrate lyase to push cytosolic acetyl-CoA levels (Hansen 2011). Remarkably, $90 \mathrm{mg} \mathrm{g}^{-1} \mathrm{DCW}$ (corresponding to $6.5 \mathrm{mg} \mathrm{L}^{-1}$ ) was reported for $Y$. lipolytica, for which the ideal promoter-gene combinations were determined for all expression cassettes (Larroude et al. 2018), while E. coli produced $72.6 \mathrm{mg} \mathrm{g}^{-1} \mathrm{DCW}$ after optimization of cultivation media composition. (Nam et al. 2013). Thus, these engineered hosts are competitive to natural microbial $\beta$-carotene producers currently used for production at industrial scale such as the microalga Dunaliella salina which has been reported to synthesize $37.3 \mathrm{mg} \mathrm{g}^{-1}$ DCW per day (García-González et al. 2005) or the fungus Blakeslea trispora which could be optimized to produce up to $55 \mathrm{mg} \mathrm{g}^{-1}$ DCW of $\beta$-carotene per day (Roukas et al. 2015). In contrast, yields of other hosts such as C. glutamicum or $P$. pastoris are relatively low in the $\mu \mathrm{g} \mathrm{g}^{-1} \mathrm{DCW}$ to singledigit $\mathrm{mg} \mathrm{g}^{-1}$ DCW range (Araya-Garay et al. 2012; Henke et al. 2016).

For the $\beta$-carotene precursor lycopene, by far, the highest reported value was for an engineered $E$. coli strain that was reported to yield $448 \mathrm{mg} \mathrm{g}^{-1} \mathrm{DCW}$ (Coussement et al. 2017). However, this report was challenged by Bian et al. (2018) very recently, claiming that due to missing and/or incomplete information, the earlier work could not be reproduced by others. For the yeasts $S$. cerevisiae (Chen et al. 2016) and Y. lipolytica (Schwartz et al. 2017), reported yields were at least one order of magnitude lower. Chen et al. (2016) produced $55.56 \mathrm{mg} \mathrm{g}^{-1}$ DCW of lycopene in a $S$. cerevisiae strain harboring several knockouts, including the YPL062W locus whose function was unclear at that time. Only very recently, it was determined by the same group that this locus functions as a promoter with major influence on terpenoid production and that a knockout positively influences production levels of all terpenoid classes (Chen et al. 2019). Respective lycopene production values for C. glutamicum or P. pastoris are markedly lower in the 1-digit $\mathrm{mg} \mathrm{g}^{-1}$ DCW range (Bhataya et al. 2009; Heider et al. 2012). A quite high yield of $82 \mathrm{mg} \mathrm{g}^{-1} \mathrm{DCW}$ was reported in a study analyzing regulatory elements in Streptomyces avermitilis that employed lycopene production as model pathway (Bai et al. 2015). In another study, the phototrophic and carotenogenic bacterium $R$. sphaeroides was further engineered to increase lycopene yields to $10 \mathrm{mg} \mathrm{g}^{-1} \mathrm{DCW}$ (Su et al. 2018). Another carotenoid recombinantly produced in microorganisms is zeaxanthin, with E. coli, P. putida, or C. glutamicum all yielding in the $\mathrm{mg} \mathrm{g}^{-1}$ DCW range (Beuttler et al. 2011; Heider et al. 2014; Shen et al. 2016). For astaxanthin, the yields reported for C. glutamicum (Henke et al. 2016), E. coli (Ma et al. 2016b), and S. cerevisiae (Zhou et al. 2017; Jin et al. 2018) are all in the low, 2-digit $\mathrm{mg} \mathrm{g}^{-1} \mathrm{DCW}$ range while production in Synechocystis PCC 6803 resulted in $1.11 \mathrm{mg} \mathrm{L}^{-1} \mathrm{~d}^{-1}$ (Albers 2016). This is still clearly lower than the values reported for microalgae, as for example the production of $77.2 \mathrm{mg} \mathrm{g}^{-1} \mathrm{DCW}$ of astaxanthin in Haematococcus pluvialis (Kang et al. 2005).

On top of the very diverse applications of carotenoids themselves, also their cleavage products, the so-called apocarotenoids, are of high commercial value. Upon action of carotenoid cleavage dioxygenases (CCDs) at double bonds 9-10 and $9^{\prime}-10^{\prime}, \beta$-ionone can be generated, which possesses interesting properties as fragrance and aroma compound. Remarkably, de novo biosynthesis of $\beta$-ionone from 
carotenoid-producing E. coli and Y. lipolytica has been yielding 500 and $380 \mathrm{mg} \mathrm{L}^{-1}$, respectively (Zhang et al. 2018a; Czajka et al. 2018). Slightly older work in S. cerevisiae had reported only around $5 \mathrm{mg} \mathrm{L}^{-1}$ (López et al. 2015). Furthermore, substantial amounts of $\alpha$-ionone $\left(480 \mathrm{mg} \mathrm{L}^{-1}\right.$ ) can be produced in engineered $E$. coli strains upon CCD cleavage of $\varepsilon$-carotene (derived from lycopene) (Zhang et al. 2018a). Expression of a $\beta$-carotene $15,15^{\prime}$-oxygenase in engineered $E$. coli led to cleavage of $\mathcal{E}$-carotene, thereby generating $600 \mathrm{mg} \mathrm{L}^{-1}$ of the vitamin A alcohol retinal (Lee et al. 2012). Although the yields were clearly lower, also the saffron spice component crocetin could be produced de novo in both E. coli and S. cerevisiae through CCD-catalyzed cleavage of zeaxanthin and subsequent oxidation catalyzed by an aldehyde dehydrogenase (Chai et al. 2017; Giuliano et al. 2018).

\section{Conclusion and future perspective}

Due to extensive, focused work on terpenoid production in $E$. coli and $S$. cerevisiae during the last two decades, these two microorganisms are the best-established hosts for a wide variety of different terpenoid compounds, in several cases already achieving industrially relevant yields (Westfall et al. 2012; Meadows et al. 2016; Larroude et al. 2018; Wang et al. 2019). However, quite a few studies on engineering of alternative hosts such as Y. lipolytica, P. pastoris, M. extorquens, or $S$. avermitilis for the production of selected terpenoid compounds demonstrated their potential, as yields are already competitive to the two "standard" hosts (Fig. 2). Especially for these novel hosts, it will be essential to analyze the impact of recombinant terpenoid production on host metabolism and accordingly adapt and balance pathway expression and regulation in order to optimize flux while avoiding feedback inhibition or toxicity by pathway intermediates. This approach will be facilitated by the wide and established range of tools for systems and synthetic biology that are available meanwhile. The positive impact of dynamic pathway regulation and metabolic balancing has been demonstrated in many recent studies for both E. coli and S. cerevisiae (Dahl et al. 2013; Xie et al. 2015; Meadows et al. 2016; Kim et al. 2016). Besides pathway engineering, also terpene synthases frequently play a major role as insufficient expression or activity can represent the major bottleneck. Selection of the bestperforming enzyme from a library of potential synthases as well as further engineering towards enhanced selectivity and catalytic efficiency can greatly improve terpenoid yields (Leonard et al. 2010; Moses et al. 2014; Edgar et al. 2017; Abdallah et al. 2018). Furthermore, the productivity of one particular terpene synthase can differ markedly when employing different hosts as demonstrated by the comparative studies of Loeschcke et al. (2017) and Beekwilder et al. (2013). These works indicate the necessity for carefully adjusting the respective host for each product individually. In addition, also proteins that are not directly involved in the pathway itself or its regulation as well as cultivation conditions can have a major influence on host productivity. Such factors, whose positive impact on terpenoid production cannot always be rationally explained yet, were for example described by Trikka et al. (2015) for $S$. cerevisiae-producing sclareol and carotenoids or in our recent work for P. pastoris that has been engineered for the production of valencene, trans-nootkatol, and nootkatone (Wriessnegger et al. 2016). Mitigation of metabolic stress elicited through recombinant terpenoid production might be the reason for the described effects. Engineering of microbes for terpenoid production would be greatly facilitated by screening procedures for enhanced terpenoid synthesis as currently only a limited number of high-throughput methods are available for selected compounds (reviewed by Emmerstorfer-Augustin et al. (2016)).

Acknowledgments We thank Dr. Anita Emmerstorfer-Augustin for the helpful comments on the manuscript.

Funding Open access funding provided by Graz University of Technology. This work has been supported by the Federal Ministry for Digital and Economic Affairs (bmwd), the Federal Ministry for Transport, Innovation and Technology (bmvit), the Styrian Business Promotion Agency SFG, the Standortagentur Tirol, the Government of Lower Austria, and the ZIT - Technology Agency of the City of Vienna through the COMET-Funding Program managed by the Austrian Research Promotion Agency FFG. The funding agencies had no influence on the conduct of this research.

\section{Compliance with ethical standards}

Conflict of interest The authors declare that they have no conflict of interest.

Ethical approval This mini review does not contain any studies with human participants or animals performed by any of the authors.

Open Access This article is distributed under the terms of the Creative Commons Attribution 4.0 International License (http:// creativecommons.org/licenses/by/4.0/), which permits unrestricted use, distribution, and reproduction in any medium, provided you give appropriate credit to the original author(s) and the source, provide a link to the Creative Commons license, and indicate if changes were made.

\section{References}

Abdallah II, van Merkerk R, Klumpenaar E, Quax WJ (2018) Catalysis of amorpha-4,11-diene synthase unraveled and improved by mutability landscape guided engineering. Sci Rep 8:9961. https://doi.org/10. 1038/s41598-018-28177-4

Abe I, Rohmer M, Prestwich GD (1993) Enzymatic cyclization of squalene and oxidosqualene to sterols and triterpenes. Chem Rev 93: 2189-2206

Ajikumar PK, Xiao WH, Tyo KEJ, Wang Y, Simeon F, Leonard E, Mucha O, Phon TH, Pfeifer B, Stephanopoulos G (2010) 
Isoprenoid pathway optimization for Taxol precursor overproduction in Escherichia coli. Science (80) 330:70-74. https://doi.org/10. $1126 /$ science. 1191652

Albers SC (2016) Metabolic engineering of the cyanobacterium Synechocystis sp. PCC 6803 for the production of astaxanthin. Colorado State University. Libraries

Albertsen L, Chen Y, Bach LS, Rattleff S, Maury J, Brix S, Nielsen J, Mortensen UH (2011) Diversion of flux toward sesquiterpene production in Saccharomyces cerevisiae. Appl Environ Microbiol 77: 1033-1040. https://doi.org/10.1128/AEM.01361-10

Albrecht M, Misawa N, Sandmann G (1999) Metabolic engineering of the terpenoid biosynthetic pathway of Escherichia coli for production of the carotenoids $\beta$-carotene and zeaxanthin. Biotechnol Lett 21:791-795. https://doi.org/10.1023/A:1005547827380

Alonso-Gutierrez J, Chan R, Batth TS, Adams PD, Keasling JD, Petzold CJ, Lee TS (2013) Metabolic engineering of Escherichia coli for limonene and perillyl alcohol production. Metab Eng 19:33-41. https://doi.org/10.1016/J.YMBEN.2013.05.004

Alonso-Gutierrez J, Kim EM, Batth TS, Cho N, Hu Q, Chan LJG, Petzold CJ, Hillson NJ, Adams PD, Keasling JD, Garcia Martin H, Lee TS (2015) Principal component analysis of proteomics (PCAP) as a tool to direct metabolic engineering. Metab Eng 28:123-133. https://doi. org/10.1016/j.ymben.2014.11.011

Anderson MS, Yarger JG, Burck CL, Poulter CD (1989) Farnesyl diphosphate synthetase. Molecular cloning, sequence, and expression of an essential gene from Saccharomyces cerevisiae. J Biol Chem 264: 19176-19184

Araya-Garay JM, Ageitos JM, Vallejo JA, Veiga-Crespo P, SánchezPérez A, Villa TG (2012) Construction of a novel Pichia pastoris strain for production of xanthophylls. AMB Express 2:24. https:// doi.org/10.1186/2191-0855-2-24

Arendt P, Miettinen K, Pollier J, De Rycke R, Callewaert N, Goossens A (2017) An endoplasmic reticulum-engineered yeast platform for overproduction of triterpenoids. Metab Eng 40:165-175. https:// doi.org/10.1016/j.ymben.2017.02.007

Asadollahi MA, Maury J, Møller K, Nielsen KF, Schalk M, Clark A, Nielsen J (2008) Production of plant sesquiterpenes in Saccharomyces cerevisiae: effect of $E R G 9$ repression on sesquiterpene biosynthesis. Biotechnol Bioeng 99:666-677. https://doi.org/ 10.1002/bit.21581

Baadhe RR, Mekala NK, Parcha SR, Prameela Devi Y (2013) Combination of $E R G 9$ repression and enzyme fusion technology for improved production of amorphadiene in Saccharomyces cerevisiae. J Anal Methods Chem 2013:1-8. https://doi.org/10. $1155 / 2013 / 140469$

Bai C, Zhang Y, Zhao X, Hu Y, Xiang S, Miao J, Lou C, Zhang L (2015) Exploiting a precise design of universal synthetic modular regulatory elements to unlock the microbial natural products in Streptomyces. Proc Natl Acad Sci 112:12181-12186. https://doi. org/10.1073/pnas.1511027112

Beekwilder J, van Houwelingen A, Cankar K, van Dijk ADJ, de Jong RM, Stoopen G, Bouwmeester H, Achkar J, Sonke T, Bosch D (2013) Valencene synthase from the heartwood of Nootka cypress (Callitropsis nootkatensis) for biotechnological production of valencene. Plant Biotechnol J 12(2):174-182. https://doi.org/10. $1111 /$ pbi.12124

Beuttler H, Hoffmann J, Jeske M, Hauer B, Schmid RD, Altenbuchner J, Urlacher VB (2011) Biosynthesis of zeaxanthin in recombinant Pseudomonas putida. Appl Microbiol Biotechnol 89:1137-1147. https://doi.org/10.1007/s00253-010-2961-0

Bhataya A, Schmidt-Dannert C, Lee PC (2009) Metabolic engineering of Pichia pastoris X-33 for lycopene production. Process Biochem 44: 1095-1102. https://doi.org/10.1016/j.procbio.2009.05.012

Bian G, Ma T, Liu T (2018) In vivo platforms for terpenoid overproduction and the generation of chemical diversity. Methods Enzymol 608:97-129. https://doi.org/10.1016/BS.MIE.2018.04.025
Biggs BW, Lim CG, Sagliani K, Shankar S, Stephanopoulos G, De Mey M, Ajikumar PK (2016) Overcoming heterologous protein interdependency to optimize P450-mediated Taxol precursor synthesis in Escherichia coli. Proc Natl Acad Sci U S A 113:3209-3214. https:// doi.org/10.1073/pnas.1515826113

Bohlmann J, Keeling CI (2008) Terpenoid biomaterials. Plant J 54:656669. https://doi.org/10.1111/j.1365-313X.2008.03449.x

Brennan TC, Turner CD, Krömer JO, Nielsen LK (2012) Alleviating monoterpene toxicity using a two-phase extractive fermentation for the bioproduction of jet fuel mixtures in Saccharomyces cerevisiae. Biotechnol Bioeng 109:2513-2522. https://doi.org/10. 1002/bit.24536

Brennan TCR, Krömer JO, Nielsen LK (2013) Physiological and transcriptional responses of Saccharomyces cerevisiae to d-limonene show changes to the cell wall but not to the plasma membrane. Appl Environ Microbiol 79:3590-3600. https://doi.org/10.1128/AEM.00463-13

Brennan TCR, Williams TC, Schulz BL, Palfreyman RW, Krömer JO, Nielsen LK (2015) Evolutionary engineering improves tolerance for replacement jet fuels in Saccharomyces cerevisiae. Appl Environ Microbiol 81:3316-3325. https://doi.org/10.1128/AEM.04144-14

Cao X, Lv Y-B, Chen J, Imanaka T, Wei L-J, Hua Q (2016) Metabolic engineering of oleaginous yeast Yarrowia lipolytica for limonene overproduction. Biotechnol Biofuels 9:214. https://doi.org/10. 1186/s13068-016-0626-7

Cao X, Wei L-J, Lin J-Y, Hua Q (2017) Enhancing linalool production by engineering oleaginous yeast Yarrowia lipolytica. Bioresour Technol 245:1641-1644. https://doi.org/10.1016/J.BIORTECH.2017.06.105

Carroll AL, Desai SH, Atsumi S (2016) Microbial production of scent and flavor compounds. Curr Opin Biotechnol 37:8-15. https://doi. org/10.1016/j.copbio.2015.09.003

Cataldo VF, López J, Cárcamo M, Agosin E (2016) Chemical vs. biotechnological synthesis of $\mathrm{C} 13$-apocarotenoids: current methods, applications and perspectives. Appl Microbiol Biotechnol 100: 5703-5718. https://doi.org/10.1007/s00253-016-7583-8

Chai F, Wang Y, Mei X, Yao M, Chen Y, Liu H, Xiao W, Yuan Y (2017) Heterologous biosynthesis and manipulation of crocetin in Saccharomyces cerevisiae. Microb Cell Factories 16:54. https:// doi.org/10.1186/s12934-017-0665-1

Chang MCY, Eachus RA, Trieu W, Ro D-K, Keasling JD (2007) Engineering Escherichia coli for production of functionalized terpenoids using plant P450s. Nat Chem Biol 3:274-277. https://doi.org/ 10.1038/nchembio875

Chen Y, Daviet L, Schalk M, Siewers V, Nielsen J (2013) Establishing a platform cell factory through engineering of yeast acetyl-CoA metabolism. Metab Eng 15:48-54. https://doi.org/10.1016/J.YMBEN.2012.11.002

Chen Y, Xiao W, Wang Y, Liu H, Li X, Yuan Y (2016) Lycopene overproduction in Saccharomyces cerevisiae through combining pathway engineering with host engineering. Microb Cell Factories 15: 113. https://doi.org/10.1186/s12934-016-0509-4

Chen Y, Wang Y, Liu M, Qu J, Yao M, Li B, Ding M, Liu H, Xiao W, Yuan Y (2019) Primary and secondary metabolic effects of a key gene deletion ( $\triangle$ YPL062W) in metabolically engineered terpenoidproducing Saccharomyces cerevisiae. Appl Environ Microbiol 85: e01990-e01918. https://doi.org/10.1128/AEM.01990-18

Cho S, Shin J, Cho B-K, Cho S, Shin J, Cho B-K (2018) Applications of CRISPR/Cas system to bacterial metabolic engineering. Int $\mathrm{J}$ Mol Sci 19:1089. https://doi.org/10.3390/ijms19041089

Choi SY, Lee HJ, Choi J, Kim J, Sim SJ, Um Y, Kim Y, Lee TS, Keasling JD, Woo HM (2016) Photosynthetic conversion of $\mathrm{CO}_{2}$ to farnesyl diphosphate-derived phytochemicals (amorpha-4,11-diene and squalene) by engineered cyanobacteria. Biotechnol Biofuels 9:202. https://doi.org/10.1186/s13068-016-0617-8

Chubukov V, Mukhopadhyay A, Petzold CJ, Keasling JD, Martín HG (2016) Synthetic and systems biology for microbial production of commodity chemicals. NPJ Syst Biol Appl 2:16009. https://doi.org/ 10.1038/npjsba.2016.9 
Coussement P, Bauwens D, Maertens J, De Mey M (2017) Direct combinatorial pathway optimization. ACS Synth Biol 6:224-232. https://doi.org/10.1021/acssynbio.6b00122

Currin A, Dunstan MS, Johannissen LO, Hollywood KA, Vinaixa M, Jervis AJ, Swainston N, Rattray NJW, Gardiner JM, Kell DB, Takano E, Toogood HS, Scrutton NS (2018) Engineering the "missing link" in biosynthetic (-)-menthol production: bacterial isopulegone isomerase. ACS Catal 8:2012-2020. https://doi.org/ 10.1021/acscatal.7b04115

Czajka JJ, Nathenson JA, Benites VT, Baidoo EEK, Cheng Q, Wang Y, Tang YJ (2018) Engineering the oleaginous yeast Yarrowia lipolytica to produce the aroma compound $\beta$-ionone. Microb Cell Factories 17:136. https://doi.org/10.1186/s12934-018-0984-x

Dahl RH, Zhang F, Alonso-Gutierrez J, Baidoo E, Batth TS, ReddingJohanson AM, Petzold CJ, Mukhopadhyay A, Lee TS, Adams PD, Keasling JD (2013) Engineering dynamic pathway regulation using stress-response promoters. Nat Biotechnol 31:1039-1046. https:// doi.org/10.1038/nbt.2689

Dai Z, Liu Y, Huang L, Zhang X (2012) Production of miltiradiene by metabolically engineered Saccharomyces cerevisiae. Biotechnol Bioeng 109:2845-2853. https://doi.org/10.1002/bit.24547

Dai Z, Liu Y, Zhang X, Shi M, Wang B, Wang D, Huang L, Zhang X (2013) Metabolic engineering of Saccharomyces cerevisiae for production of ginsenosides. Metab Eng 20:146-156. https://doi.org/10. 1016/j.ymben.2013.10.004

Dai Z, Wang B, Liu Y, Shi M, Wang D, Zhang X, Liu T, Huang L, Zhang $X$ (2014) Producing aglycons of ginsenosides in bakers' yeast. Sci Rep 4:3698. https://doi.org/10.1038/srep03698

Daum G, Lees ND, Bard M, Dickson R (1998) Biochemistry, cell biology and molecular biology of lipids of Saccharomyces cerevisiae. Yeast 14:1471-1510. https://doi.org/10.1002/(SICI)1097-0061(199812) 14:16<1471::AID-YEA353>3.0.CO;2-Y

Davies FK, Work VH, Beliaev AS, Posewitz MC (2014) Engineering limonene and bisabolene production in wild type and a glycogendeficient mutant of Synechococcus sp. PCC 7002. Front Bioeng Biotechnol 2:21. https://doi.org/10.3389/fbioe.2014.00021

Ding M, Yan H, Li L, Zhai F, Shang L, Yin Z, Yuan Y (2014) Biosynthesis of taxadiene in Saccharomyces cerevisiae : selection of geranylgeranyl diphosphate synthase directed by a computeraided docking strategy. PLoS One 9:e109348. https://doi.org/10. 1371/journal.pone.0109348

Dunlop MJ, Dossani ZY, Szmidt HL, Chu HC, Lee TS, Keasling JD, Hadi MZ, Mukhopadhyay A (2011) Engineering microbial biofuel tolerance and export using efflux pumps. Mol Syst Biol 7:487. https://doi.org/10.1038/msb.2011.21

Edgar S, Li F-S, Qiao K, Weng J-K, Stephanopoulos G (2017) Engineering of taxadiene synthase for improved selectivity and yield of a key Taxol biosynthetic intermediate. ACS Synth Biol 6:201205. https://doi.org/10.1021/acssynbio.6b00206

Emmerstorfer A, Wimmer-Teubenbacher M, Wriessnegger T, Leitner E, Müller, Kaluzna I, Schürmann M, Mink D, Zellnig G, Schwab H, Pichler H (2015) Over-expression of ICE2 stabilizes cytochrome P450 reductase in Saccharomyces cerevisiae and Pichia pastoris. Biotechnol J 10:623-635. https://doi.org/10.1002/biot.201400780

Emmerstorfer-Augustin A, Moser S, Pichler H (2016) Screening for improved isoprenoid biosynthesis in microorganisms. J Biotechnol 235:112-120. https://doi.org/10.1016/j.jbiotec.2016.03.051

Engels B, Dahm P, Jennewein S (2008) Metabolic engineering of taxadiene biosynthesis in yeast as a first step towards Taxol (paclitaxel) production. Metab Eng 10:201-206. https://doi.org/10. 1016/j.ymben.2008.03.001

Farhi M, Marhevka E, Masci T, Marcos E, Eyal Y, Ovadis M, Abeliovich H, Vainstein A (2011) Harnessing yeast subcellular compartments for the production of plant terpenoids. Metab Eng 13:474-481. https://doi.org/10.1016/j.ymben.2011.05.001
Fischer MJC, Meyer S, Claudel P, Bergdoll M, Karst F (2011) Metabolic engineering of monoterpene synthesis in yeast. Biotechnol Bioeng 108:1883-1892. https://doi.org/10.1002/bit.23129

Formighieri C, Melis A (2016) Sustainable heterologous production of terpene hydrocarbons in cyanobacteria. Photosynth Res 130:123135. https://doi.org/10.1007/s11120-016-0233-2

Formighieri C, Melis A (2017) Heterologous synthesis of geranyllinalool, a diterpenol plant product, in the cyanobacterium Synechocystis. Appl Microbiol Biotechnol 101:2791-2800. https://doi.org/10. 1007/s00253-016-8081-8

Frohwitter J, Heider SAE, Peters-Wendisch P, Beekwilder J, Wendisch VF (2014) Production of the sesquiterpene (+)-valencene by metabolically engineered Corynebacterium glutamicum. J Biotechnol 191:205-213. https://doi.org/10.1016/j.jbiotec.2014.05.032

García-González M, Moreno J, Manzano JC, Florencio FJ, Guerrero MG (2005) Production of Dunaliella salina biomass rich in 9-cis- $\beta$ carotene and lutein in a closed tubular photobioreactor. J Biotechnol 115:81-90. https://doi.org/10.1016/J.JBIOTEC.2004.07.010

George KW, Alonso-Gutierrez J, Keasling JD, Lee TS (2015) Isoprenoid drugs, biofuels, and chemicals-artemisinin, farnesene, and beyond. In: Schrader J, Bohlmann J (eds) Advances in biochemical engineering/ biotechnology. Springer International Publishing, Cham, pp 355-389

Gershenzon J, Dudareva N (2007) The function of terpene natural products in the natural world. Nat Chem Biol 3:408-414. https://doi.org/ 10.1038/nchembio.2007.5

Giuliano G, Ferrante P, Frusciante S, Diretto G, Pietrella M, Al-Babili S (2018) Carotenoid dioxygenase and methods for the biotechnological production in microorganisms and plants of compounds derived from saffron US9969989B2

Gruchattka E, Hädicke O, Klamt S, Schütz V, Kayser O (2013) In silico profiling of Escherichia coli and Saccharomyces cerevisiae as terpenoid factories. Microb Cell Factories 12:84. https://doi.org/10. 1186/1475-2859-12-84

Han GH, Kim SK, Yoon PK-S, Kang Y, Kim BS, Fu Y, Sung BH, Jung HC, Lee D-H, Kim S-W, Lee S-G (2016) Fermentative production and direct extraction of $(-)-\alpha$-bisabolol in metabolically engineered Escherichia coli. Microb Cell Factories 15:185. https://doi.org/10. 1186/s12934-016-0588-2

Hansen J (2011) Method of producing isoprenoid compounds in yeast WO2011146833A1

Heider SAE, Peters-Wendisch P, Wendisch VF (2012) Carotenoid biosynthesis and overproduction in Corynebacterium glutamicum. BMC Microbiol 12:198. https://doi.org/10.1186/1471-2180-12-198

Heider SAE, Wolf N, Hofemeier A, Peters-Wendisch P, Wendisch VF (2014) Optimization of the IPP precursor supply for the production of lycopene, decaprenoxanthin and astaxanthin by Corynebacterium glutamicum. Front Bioeng Biotechnol 2:28. https://doi.org/10.3389/ fbioe. 2014.00028

Henke NA, Heider SAE, Peters-Wendisch P, Wendisch VF (2016) Production of the marine carotenoid astaxanthin by metabolically engineered Corynebacterium glutamicum. Mar Drugs 14:124. https://doi.org/10.3390/md14070124

Henke NA, Wichmann J, Baier T, Frohwitter J, Lauersen KJ, Risse JM, Peters-Wendisch P, Kruse O, Wendisch VF (2018) Patchoulol production with metabolically engineered Corynebacterium glutamicum. Genes (Basel) 9:219. https://doi.org/10.3390/genes9040219

Hirte M, Mischko W, Kemper K, Röhrer S, Huber C, Fuchs M, Eisenreich W, Minceva M, Brück TB (2018) From microbial upcycling to biology-oriented synthesis: combining whole-cell production and chemo-enzymatic functionalization for sustainable taxanoid delivery. Green Chem 20:5374-5384. https://doi.org/10. 1039/C8GC03126F

Ignea C, Cvetkovic I, Loupassaki S, Kefalas P, Johnson CB, Kampranis SC, Makris AM (2011) Improving yeast strains using recyclable integration cassettes, for the production of plant terpenoids. Microb Cell Factories 10:4. https://doi.org/10.1186/1475-2859-10-4 
Ignea C, Trikka FA, Nikolaidis AK, Georgantea P, Ioannou E, Loupassaki S, Kefalas P, Kanellis AK, Roussis V, Makris AM, Kampranis SC (2015) Efficient diterpene production in yeast by engineering Erg20p into a geranylgeranyl diphosphate synthase. Metab Eng 27:65-75. https://doi.org/10.1016/j.ymben.2014.10.008

Ikeda M, Takeno S (2013) Amino acid production by Corynebacterium glutamicum. In: Yukawa H, Inui M (eds) Corynebacterium glutamicum. Springer, Berlin, Heidelberg, pp 107-147

Jansen DJ, Shenvi RA (2014) Synthesis of medicinally relevant terpenes: reducing the cost and time of drug discovery. Future Med Chem 6: 1127-1148. https://doi.org/10.4155/fmc. 14.71

Jennewein S, Wildung MR, Chau M, Walker K, Croteau R (2004) Random sequencing of an induced Taxus cell cDNA library for identification of clones involved in Taxol biosynthesis. Proc Natl Acad Sci U S A 101:9149-9154. https://doi.org/10.1073/pnas. 0403009101

Jiang Y, Proteau P, Poulter D, Ferro-Novick S (1995) BTS1 encodes a geranylgeranyl diphosphate synthase in Saccharomyces cerevisiae. J Biol Chem 270:21793-21799

Jiang GZ, Yao MD, Wang Y, Zhou L, Song TQ, Liu H, Xiao WH, Yuan YJ (2017) Manipulation of GES and ERG20 for geraniol overproduction in Saccharomyces cerevisiae. Metab Eng 41:57-66. https:// doi.org/10.1016/j.ymben.2017.03.005

Jin J, Wang Y, Yao M, Gu X, Li B, Liu H, Ding M, Xiao W, Yuan Y (2018) Astaxanthin overproduction in yeast by strain engineering and new gene target uncovering. Biotechnol Biofuels 11:230. https://doi.org/10.1186/s13068-018-1227-4

Kang CD, Lee JS, Park TH, Sim SJ (2005) Comparison of heterotrophic and photoautotrophic induction on astaxanthin production by Haematococcus pluvialis. Appl Microbiol Biotechnol 68:237-241. https://doi.org/10.1007/s00253-005-1889-2

Kang MK, Eom JH, Kim Y, Um Y, Woo HM (2014) Biosynthesis of pinene from glucose using metabolically-engineered Corynebacterium glutamicum. Biotechnol Lett 36:2069-2077. https://doi.org/10.1007/s10529-014-1578-2

Kemper K, Hirte M, Reinbold M, Fuchs M, Brück T (2017) Opportunities and challenges for the sustainable production of structurally complex diterpenoids in recombinant microbial systems. Beilstein J Org Chem 13:845-854. https://doi.org/10.3762/bjoc.13.85

Khalid A, Takagi H, Panthee S, Muroi M, Chappell J, Osada H, Takahashi S (2017) Development of a terpenoid-production platform in Streptomyces reveromyceticus SN-593. ACS Synth Biol 6: 2339-2349. https://doi.org/10.1021/acssynbio.7b00249

Khan NE, Nybo SE, Chappell J, Curtis WR (2015) Triterpene hydrocarbon production engineered into a metabolically versatile hostRhodobacter capsulatus. Biotechnol Bioeng 112:1523-1532. https://doi.org/10.1002/bit.25573

Kim S-W, Keasling JD (2001) Metabolic engineering of the nonmevalonate isopentenyl diphosphate synthesis pathway in Escherichia coli enhances lycopene production. Biotechnol Bioeng 72:408-415. https://doi.org/10.1002/1097-0290(20000220) 72:4<408::AID-BIT1003>3.0.CO;2-H

Kim SK, Han GH, Seong W, Kim H, Kim S-W, Lee D-H, Lee S-G (2016) CRISPR interference-guided balancing of a biosynthetic mevalonate pathway increases terpenoid production. Metab Eng 38:228-240. https://doi.org/10.1016/J.YMBEN.2016.08.006

Kirby J, Dietzel KL, Wichmann G, Chan R, Antipov E, Moss N, Baidoo EEK, Jackson P, Gaucher SP, Gottlieb S, LaBarge J, Mahatdejkul T, Hawkins KM, Muley S, Newman JD, Liu P, Keasling JD, Zhao L (2016) Engineering a functional 1-deoxy-D-xylulose 5-phosphate (DXP) pathway in Saccharomyces cerevisiae. Metab Eng 38:494503. https://doi.org/10.1016/j.ymben.2016.10.017

Krieg T, Sydow A, Faust S, Huth I, Holtmann D (2018) $\mathrm{CO}_{2}$ to terpenes: autotrophic and electroautotrophic $\alpha$-humulene production with Cupriavidus necator. Angew Chem Int Ed 57:1879-1882. https:// doi.org/10.1002/anie.201711302
Larroude M, Celinska E, Back A, Thomas S, Nicaud J-M, LedesmaAmaro R (2018) A synthetic biology approach to transform Yarrowia lipolytica into a competitive biotechnological producer of $\beta$-carotene. Biotechnol Bioeng 115:464-472. https://doi.org/10. 1002/bit.26473

Laurent P, Braekman J-C, Daloze D, Pasteels J (2003) Biosynthesis of defensive compounds from beetles and ants. Eur J Org Chem 2003: 2733-2743. https://doi.org/10.1002/ejoc.200300008

Lee J-H, Choi J-G, Kim Y-S, Kim K-R, Kim S-W, Oh D-K (2012) Enhancement of retinal production by supplementing the surfactant Span 80 using metabolically engineered Escherichia coli. J Biosci Bioeng 113:461-466. https://doi.org/10.1016/J.JBIOSC.2011.11.020

Lee HJ, Lee J, Lee S-M, Um Y, Kim Y, Sim SJ, Choi J, Woo HM (2017) Direct conversion of $\mathrm{CO}_{2}$ to $\alpha$-farnesene using metabolically engineered Synechococcus elongatus PCC 7942. J Agric Food Chem 65:10424-10428. https://doi.org/10.1021/acs.jafc.7b03625

Leonard E, Ajikumar PK, Thayer K, Xiao W-HW-H, Mo JD, Tidor B, Stephanopoulos G, Prather KLJ (2010) Combining metabolic and protein engineering of a terpenoid biosynthetic pathway for overproduction and selectivity control. Proc Natl Acad Sci 107:13654 13659. https://doi.org/10.1073/pnas.1006138107

Li YF, Wang G (2016) Strategies of isoprenoids production in engineered bacteria. J Appl Microbiol 121:932-940. https://doi.org/10.1111/ jam. 13237

Li Q, Sun Z, Li J, Zhang Y (2013) Enhancing beta-carotene production in Saccharomyces cerevisiae by metabolic engineering. FEMS Microbiol Lett 345:94-101. https://doi.org/10.1111/1574-6968.12187

Li D, Zhang Q, Zhou Z, Zhao F, Lu W (2016) Heterologous biosynthesis of triterpenoid dammarenediol-II in engineered Escherichia coli. Biotechnol Lett 38:603-609. https://doi.org/10.1007/s10529-0152032-9

Li M, Nian R, Xian M, Zhang H (2018) Metabolic engineering for the production of isoprene and isopentenol by Escherichia coli. Appl Microbiol Biotechnol 102:7725-7738. https://doi.org/10.1007/ s00253-018-9200-5

Liang H, Hu Z, Zhang T, Gong T, Chen J, Zhu P, Li Y, Yang J (2017) Production of a bioactive unnatural ginsenoside by metabolically engineered yeasts based on a new UDP-glycosyltransferase from Bacillus subtilis. Metab Eng 44:60-69. https://doi.org/10.1016/J. YMBEN.2017.07.008

Loeschcke A, Dienst D, Wewer V, Hage-Hülsmann J, Dietsch M, KranzFinger S, Hüren V, Metzger S, Urlacher VB, Gigolashvili T, Kopriva S, Axmann IM, Drepper T, Jaeger K-E (2017) The photosynthetic bacteria Rhodobacter capsulatus and Synechocystis sp. PCC 6803 as new hosts for cyclic plant triterpene biosynthesis. PLoS One 12: e0189816. https://doi.org/10.1371/journal.pone.0189816

López J, Essus K, Kim I, Pereira R, Herzog J, Siewers V, Nielsen J, Agosin E (2015) Production of $\beta$-ionone by combined expression of carotenogenic and plant CCD1 genes in Saccharomyces cerevisiae. Microb Cell Factories 14:84. https://doi.org/10.1186/ s12934-015-0273-x

Lu C, Zhang C, Zhao F, Li D, Lu W (2018) Biosynthesis of ursolic acid and oleanolic acid in Saccharomyces cerevisiae. AICHE J 64:3794 3802. https://doi.org/10.1002/aic. 16370

Ma T, Deng Z, Liu T (2016a) Microbial production strategies and applications of lycopene and other terpenoids. World J Microbiol Biotechnol 32:15. https://doi.org/10.1007/s11274-015-1975-2

Ma T, Zhou Y, Li X, Zhu F, Cheng Y, Liu Y, Deng Z, Liu T (2016b) Genome mining of astaxanthin biosynthetic genes from Sphingomonas sp. ATCC 55669 for heterologous overproduction in Escherichia coli. Biotechnol J 11:228-237. https://doi.org/10. 1002/biot.201400827

Martin VJJ, Pitera DJ, Withers ST, Newman JD, Keasling JD (2003) Engineering a mevalonate pathway in Escherichia coli for production of terpenoids. Nat Biotechnol 21:796-802. https://doi.org/10. $1038 /$ nbt833 
Matthäus F, Ketelhot M, Gatter M, Barth G (2014) Production of lycopene in the non-carotenoid-producing yeast Yarrowia lipolytica. Appl Environ Microbiol 80:1660-1669. https://doi.org/10.1128/ AEM.03167-13

Meadows AL, Hawkins KM, Tsegaye Y, Antipov E, Kim Y, Raetz L, Dahl RH, Tai A, Mahatdejkul-Meadows T, Xu L, Zhao L, Dasika MS, Murarka A, Lenihan J, Eng D, Leng JS, Liu C-L, Wenger JW, Jiang H, Chao L, Westfall P, Lai J, Ganesan S, Jackson P, Mans R, Platt D, Reeves CD, Saija PR, Wichmann G, Holmes VF, Benjamin K, Hill PW, Gardner TS, Tsong AE (2016) Rewriting yeast central carbon metabolism for industrial isoprenoid production. Nature 537: 694-697. https://doi.org/10.1038/nature19769

Mi J, Becher D, Lubuta P, Dany S, Tusch K, Schewe H, Buchhaupt M, Schrader J (2014) De novo production of the monoterpenoid geranic acid by metabolically engineered Pseudomonas putida. Microb Cell Factories 13:170. https://doi.org/10.1186/s12934-014-0170-8

Mi J, Schewe H, Buchhaupt M, Holtmann D, Schrader J (2016) Efficient hydroxylation of 1,8-cineole with monoterpenoid-resistant recombinant Pseudomonas putida GS1. World J Microbiol Biotechnol 32: 112. https://doi.org/10.1007/s11274-016-2071-y

Millis J, Maurina-Brunker J, McMullin T (2001) Production of farnesol and geranylgeraniol US6689593B2

Mirata MA, Heerd D, Schrader J (2009) Integrated bioprocess for the oxidation of limonene to perillic acid with Pseudomonas putida DSM 12264. Process Biochem 44:764-771. https://doi.org/10. 1016/J.PROCBIO.2009.03.013

Miziorko HM (2011) Enzymes of the mevalonate pathway of isoprenoid biosynthesis. Arch Biochem Biophys 505:131-143. https://doi.org/ 10.1016/J.ABB.2010.09.028

Morrone D, Lowry L, Determan MK, Hershey DM, Xu M, Peters RJ (2010) Increasing diterpene yield with a modular metabolic engineering system in E. coli: comparison of MEV and MEP isoprenoid precursor pathway engineering. Appl Microbiol Biotechnol 85: 1893-1906. https://doi.org/10.1007/s00253-009-2219-x

Moser S, Strohmeier GA, Leitner E, Plocek TJ, Vanhessche K, Pichler H (2018) Whole-cell (+)-ambrein production in the yeast Pichia pastoris. Metab Eng Commun 7:e00077. https://doi.org/10.1016/j. mec.2018.e00077

Moses T, Thevelein JM, Goossens A, Pollier J (2014) Comparative analysis of CYP93E proteins for improved microbial synthesis of plant triterpenoids. Phytochemistry 108:47-56. https://doi.org/10.1016/J. PHYTOCHEM.2014.10.002

Nam H-K, Choi J-G, Lee J-H, Kim S-W, Oh D-K (2013) Increase in the production of $\beta$-carotene in recombinant Escherichia coli cultured in a chemically defined medium supplemented with amino acids. Biotechnol Lett 35:265-271. https://doi.org/10.1007/s10529-012-1072-7

Niehus X, Crutz-Le Coq A-M, Sandoval G, Nicaud J-M, LedesmaAmaro R (2018) Engineering Yarrowia lipolytica to enhance lipid production from lignocellulosic materials. Biotechnol Biofuels 11: 11. https://doi.org/10.1186/s13068-018-1010-6

Nielsen DR, Leonard E, Yoon S-H, Tseng H-C, Yuan C, Prather KLJ (2009) Engineering alternative butanol production platforms in heterologous bacteria. Metab Eng 11:262-273. https://doi.org/10.1016/ J.YMBEN.2009.05.003

Özaydın B, Burd H, Lee TS, Keasling JD (2013) Carotenoid-based phenotypic screen of the yeast deletion collection reveals new genes with roles in isoprenoid production. Metab Eng 15:174-183. https://doi.org/10.1016/j.ymben.2012.07.010

Paddon CJ, Westfall PJ, Pitera DJ, Benjamin K, Fisher K, McPhee D, Leavell MD, Tai A, Main A, Eng D, Polichuk DR, Teoh KH, Reed DW, Treynor T, Lenihan J, Fleck M, Bajad S, Dang G, Dengrove D, Diola D, Dorin G, Ellens KW, Fickes S, Galazzo J, Gaucher SP, Geistlinger T, Henry R, Hepp M, Horning T, Iqbal T, Jiang H, Kizer L, Lieu B, Melis D, Moss N, Regentin R, Secrest S, Tsuruta $\mathrm{H}$, Vazquez R, Westblade LF, Xu L, Yu M, Zhang Y, Zhao L, Lievense J, Covello PS, Keasling JD, Reiling KK, Renninger NS,
Newman JD (2013) High-level semi-synthetic production of the potent antimalarial artemisinin. Nature 496:528-532. https://doi. org/10.1038/nature12051

Paramasivan K, Mutturi S (2017) Progress in terpene synthesis strategies through engineering of Saccharomyces cerevisiae. Crit Rev Biotechnol 37:974-989. https://doi.org/10.1080/07388551.2017. 1299679

Pattanaik B, Lindberg P (2015) Terpenoids and their biosynthesis in cyanobacteria. Life (Basel, Switzerland) 5:269-293. https://doi. org/10.3390/life5010269

Peng B, Plan MR, Chrysanthopoulos P, Hodson MP, Nielsen LK, Vickers CE (2017) A squalene synthase protein degradation method for improved sesquiterpene production in Saccharomyces cerevisiae. Metab Eng 39: 209-219. https://doi.org/10.1016/J.YMBEN.2016.12.003

Peng B, Nielsen LK, Kampranis SC, Vickers CE (2018) Engineered protein degradation of farnesyl pyrophosphate synthase is an effective regulatory mechanism to increase monoterpene production in Saccharomyces cerevisiae. Metab Eng 47:83-93. https://doi.org/10. 1016/j.ymben.2018.02.005

Phelan RM, Sekurova ON, Keasling JD, Zotchev SB (2015) Engineering terpene biosynthesis in Streptomyces for production of the advanced biofuel precursor bisabolene. ACS Synth Biol 4:393-399. https:// doi.org/10.1021/sb5002517

Pichersky E, Raguso RA (2016) Why do plants produce so many terpenoid compounds? New Phytol 220:692-702. https://doi.org/10. 1111/nph.14178

Quin MB, Flynn CM, Schmidt-Dannert C (2014) Traversing the fungal terpenome. Nat Prod Rep 31:1449-1473. https://doi.org/10.1039/ C4NP00075G

Raschmanová H, Weninger A, Glieder A, Kovar K, Vogl T (2018) Implementing CRISPR-Cas technologies in conventional and nonconventional yeasts: current state and future prospects. Biotechnol Adv 36:641-665. https://doi.org/10.1016/j.biotechadv.2018.01.006

Reinsvold RE, Jinkerson RE, Radakovits R, Posewitz MC, Basu C (2011) The production of the sesquiterpene $\beta$-caryophyllene in a transgenic strain of the cyanobacterium Synechocystis. J Plant Physiol 168:848852. https://doi.org/10.1016/J.JPLPH.2010.11.006

Renault H, Bassard J-E, Hamberger B, Werck-Reichhart D (2014) Cytochrome P450-mediated metabolic engineering: current progress and future challenges. Curr Opin Plant Biol 19:27-34. https:// doi.org/10.1016/J.PBI.2014.03.004

Ro D-K, Paradise EM, Ouellet M, Fisher KJ, Newman KL, Ndungu JM, Ho KA, Eachus RA, Ham TS, Kirby J, Chang MCY, Withers ST, Shiba Y, Sarpong R, Keasling JD (2006) Production of the antimalarial drug precursor artemisinic acid in engineered yeast. Nature 440:940-943. https://doi.org/10.1038/nature04640

Rohmer M (1999) The discovery of a mevalonate-independent pathway for isoprenoid biosynthesis in bacteria, algae and higher plants. Nat Prod Rep 16:565-574

Roukas T, Varzakakou M, Kotzekidou P (2015) From cheese whey to carotenes by Blakeslea trispora in a bubble column reactor. Appl Biochem Biotechnol 175:182-193. https://doi.org/10.1007/s12010-014-1260-0

Sandmann G (2002) Molecular evolution of carotenoid biosynthesis from bacteria to plants. Physiol Plant 116:431-440. https://doi.org/10. 1034/j.1399-3054.2002.1160401.x

Sardessai Y, Bhosle S (2002) Tolerance of bacteria to organic solvents. Res Microbiol 153:263-268. https://doi.org/10.1016/S09232508(02)01319-0

Sato $\mathrm{T}$ (2013) Unique biosynthesis of sesquarterpenes (C35 terpenes). Biosci Biotechnol Biochem 77:1155-1159. https://doi.org/10. 1271/bbb. 130180

Scalcinati G, Knuf C, Partow S, Chen Y, Maury J, Schalk M, Daviet L, Nielsen J, Siewers V (2012) Dynamic control of gene expression in Saccharomyces cerevisiae engineered for the production of plant sesquitepene $\alpha$-santalene in a fed-batch mode. Metab Eng 14:91103. https://doi.org/10.1016/j.ymben.2012.01.007 
Schalk M, Pastore L, Mirata MA, Khim S, Schouwey M, Deguerry F, Pineda V, Rocci L, Daviet L (2012) Toward a biosynthetic route to sclareol and amber odorants. J Am Chem Soc 134:18900-18903. https://doi.org/10.1021/ja307404u

Schallmey M, Singh A, Ward OP (2004) Developments in the use of Bacillus species for industrial production. Can J Microbiol 50:117. https://doi.org/10.1139/w03-076

Schempp FM, Drummond L, Buchhaupt M, Schrader J (2018) Microbial cell factories for the production of terpenoid flavor and fragrance compounds. J Agric Food Chem 66(10):2247-2258. https://doi.org/ 10.1021/acs.jafc.7b00473

Schwartz C, Frogue K, Misa J, Wheeldon I (2017) Host and pathway engineering for enhanced lycopene biosynthesis in Yarrowia lipolytica. Front Microbiol 8:2233. https://doi.org/10.3389/fmicb.2017.02233

Shen H-J, Cheng B-Y, Zhang Y-M, Tang L, Li Z, Bu Y-F, Li X-R, Tian GQ, Liu J-Z (2016) Dynamic control of the mevalonate pathway expression for improved zeaxanthin production in Escherichia coli and comparative proteome analysis. Metab Eng 38:180-190. https:// doi.org/10.1016/J.YMBEN.2016.07.012

Shiba Y, Paradise EM, Kirby J, Ro D-K, Keasling JD (2007) Engineering of the pyruvate dehydrogenase bypass in Saccharomyces cerevisiae for high-level production of isoprenoids. Metab Eng 9:160-168. https://doi.org/10.1016/j.ymben.2006.10.005

Sikkema J, de Bont JA, Poolman B (1995) Mechanisms of membrane toxicity of hydrocarbons. Microbiol Mol Biol Rev 59:201-222

Šobotník J, Jirošová A, Hanus R (2010) Chemical warfare in termites. J Insect Physiol 56:1012-1021. https://doi.org/10.1016/J.JINSPHYS. 2010.02.012

Sonntag F, Kroner C, Lubuta P, Peyraud R, Horst A, Buchhaupt M, Schrader J (2015) Engineering Methylobacterium extorquens for de novo synthesis of the sesquiterpenoid $\alpha$-humulene from methanol. Metab Eng 32: 82-94. https://doi.org/10.1016/J.YMBEN.2015.09.004

Speelmans G, Bijlsma A, Eggink G (1998) Limonene bioconversion to high concentrations of a single and stable product, perillic acid, by a solvent-resistant Pseudomonas putida strain. Appl Microbiol Biotechnol 50:538-544. https://doi.org/10.1007/s002530051331

Su A, Chi S, Li Y, Tan S, Qiang S, Chen Z, Meng Y (2018) Metabolic redesign of Rhodobacter sphaeroides for lycopene production. J Agric Food Chem 66:5879-5885. https://doi.org/10.1021/acs.jafc. $8 \mathrm{~b} 00855$

Suffness M (1995) Taxol : science and applications. CRC Press, Boca Raton

Swiezewska E, Danikiewicz W (2005) Polyisoprenoids: structure, biosynthesis and function. Prog Lipid Res 44:235-258. https://doi.org/ 10.1016/J.PLIPRES.2005.05.002

Tabata K, Hashimoto S-I (2004) Production of mevalonate by a metabolically-engineered Escherichia coli. Biotechnol Lett 26: 1487-1491. https://doi.org/10.1023/B:BILE.0000044449.08268.7d

Tai M, Stephanopoulos G (2013) Engineering the push and pull of lipid biosynthesis in oleaginous yeast Yarrowia lipolytica for biofuel production. Metab Eng 15:1-9. https://doi.org/10.1016/J.YMBEN. 2012.08.007

Takahashi S, Yeo Y, Greenhagen BT, McMullin T, Song L, MaurinaBrunker J, Rosson R, Noel JP, Chappell J (2007) Metabolic engineering of sesquiterpene metabolism in yeast. Biotechnol Bioeng 97:170-181. https://doi.org/10.1002/bit.21216

Thulasiram HV, Poulter CD (2006) Farnesyl diphosphate synthase: the art of compromise between substrate selectivity and stereoselectivity. J Am Chem Soc 128:15819. https://doi.org/10.1021/JA065573B

Tokuhiro K, Muramatsu M, Ohto C, Kawaguchi T, Obata S, Muramoto N, Hirai M, Takahashi H, Kondo A, Sakuradani E, Shimizu S (2009) Overproduction of geranylgeraniol by metabolically engineered Saccharomyces cerevisiae. Appl Environ Microbiol 75:55365543. https://doi.org/10.1128/AEM.00277-09

Toogood HS, Cheallaigh AN, Tait S, Mansell DJ, Jervis A, Lygidakis A, Humphreys L, Takano E, Gardiner JM, Scrutton NS (2015)
Enzymatic menthol production: one-pot approach using engineered Escherichia coli. ACS Synth Biol 4:1112-1123. https://doi.org/10. 1021/acssynbio.5b00092

Trikka FA, Nikolaidis A, Athanasakoglou A, Andreadelli A, Ignea C, Kotta K, Argiriou A, Kampranis SC, Makris AM (2015) Iterative carotenogenic screens identify combinations of yeast gene deletions that enhance sclareol production. Microb Cell Factories 14:60. https://doi.org/10.1186/s12934-015-0246-0

Trombetta D, Castelli F, Sarpietro MG, Venuti V, Cristani M, Daniele C, Saija A, Mazzanti G, Bisignano G (2005) Mechanisms of antibacterial action of three monoterpenes. Antimicrob Agents Chemother 49:2474-2478. https://doi.org/10.1128/AAC.49.6.2474-2478.2005

Tsuruta H, Paddon CJ, Eng D, Lenihan JR, Horning T, Anthony LC, Regentin R, Keasling JD, Renninger NS, Newman JD (2009) High-level production of amorpha-4, 11-diene, a precursor of the antimalarial agent artemisinin, in Escherichia coli. PLoS One 4: e4489. https://doi.org/10.1371/journal.pone.0004489

Turner GW, Croteau R (2004) Organization of monoterpene biosynthesis in Mentha. Immunocytochemical localizations of geranyl diphosphate synthase, limonene-6-hydroxylase, isopiperitenol dehydrogenase, and pulegone reductase. Plant Physiol 136:4215-4227. https:// doi.org/10.1104/pp.104.050229

Vavitsas K, Rue EØ, Stefánsdóttir LK, Gnanasekaran T, Blennow A, Crocoll C, Gudmundsson S, Jensen PE (2017) Responses of Synechocystis sp. PCC 6803 to heterologous biosynthetic pathways. Microb Cell Factories 16:140. https://doi.org/10.1186/s12934-017-0757-y

Vickers CE, Williams TC, Peng B, Cherry J (2017) Recent advances in synthetic biology for engineering isoprenoid production in yeast. Curr Opin Chem Biol 40:47-56. https://doi.org/10.1016/j.cbpa.2017.05.017

Vogl T, Glieder A, Ajikumar PK (2016) Production of terpenes and terpenoids US20180094286A1

Wang G, Tang W, Bidigare RR (2005) Terpenoids as therapeutic drugs and pharmaceutical agents. In: Zhang L, Demain A (eds) Natural products. Humana Press, Totowa, pp 197-227

Wang C, Yoon S-H, Jang H-J, Chung Y-R, Kim J-Y, Choi E-S, Kim S-W (2011) Metabolic engineering of Escherichia coli for $\alpha$-farnesene production. Metab Eng 13:648-655. https://doi.org/10.1016/J. YMBEN.2011.08.001

Wang L, Yang B, Lin X-P, Zhou X-F, Liu Y (2013a) Sesterterpenoids. Nat Prod Rep 30:455. https://doi.org/10.1039/c3np20089b

Wang Y, Lim L, DiGuistini S, Robertson G, Bohlmann J, Breuil C (2013b) A specialized ABC efflux transporter GcABC-G1 confers monoterpene resistance to Grosmannia clavigera , a bark beetleassociated fungal pathogen of pine trees. New Phytol 197:886898. https://doi.org/10.1111/nph.12063

Wang P, Wei Y, Fan Y, Liu Q, Wei W, Yang C, Zhang L, Zhao G, Yue J, Yan X, Zhou Z (2015) Production of bioactive ginsenosides Rh2 and $\operatorname{Rg} 3$ by metabolically engineered yeasts. Metab Eng 29:97-105. https://doi.org/10.1016/j.ymben.2015.03.003

Wang P, Wei W, Ye W, Li X, Zhao W, Yang C, Li C, Yan X, Zhou Z (2019) Synthesizing ginsenoside Rh2 in Saccharomyces cerevisiae cell factory at high-efficiency. Cell Discov 5:5. https://doi.org/10. 1038/s41421-018-0075-5

Ward VCA, Chatzivasileiou AO, Stephanopoulos G (2018) Metabolic engineering of Escherichia coli for the production of isoprenoids. FEMS Microbiol Lett 365:fny079. https://doi.org/10.1093/femsle/ fny079

Wei N, Oh EJ, Million G, Cate JHD, Jin Y-S (2015a) Simultaneous utilization of cellobiose, xylose, and acetic acid from lignocellulosic biomass for biofuel production by an engineered yeast platform. ACS Synth Biol 4:707-713. https://doi.org/10.1021/sb500364q

Wei W, Wang P, Wei Y, Liu Q, Yang C, Zhao G, Yue J, Yan X, Zhou Z (2015b) Characterization of Panax ginseng UDP-glycosyltransferases catalyzing protopanaxatriol and biosyntheses of bioactive ginsenosides F1 and Rh1 in metabolically engineered yeasts. Mol Plant 8:14121424. https://doi.org/10.1016/J.MOLP.2015.05.010 
Wendisch VF, Brito LF, Gil Lopez M, Hennig G, Pfeifenschneider J, Sgobba E, Veldmann KH (2016) The flexible feedstock concept in industrial biotechnology: metabolic engineering of Escherichia coli, Corynebacterium glutamicum, Pseudomonas, Bacillus and yeast strains for access to alternative carbon sources. J Biotechnol 234: 139-157. https://doi.org/10.1016/J.JBIOTEC.2016.07.022

Westfall PJ, Pitera DJ, Lenihan JR, Eng D, Woolard FX, Regentin R, Horning T, Tsuruta H, Melis DJ, Owens A, Fickes S, Diola D, Benjamin KR, Keasling JD, Leavell MD, McPhee DJ, Renninger NS, Newman JD, Paddon CJ (2012) Production of amorphadiene in yeast, and its conversion to dihydroartemisinic acid, precursor to the antimalarial agent artemisinin. Proc Natl Acad Sci U S A 109:E111E118. https://doi.org/10.1073/pnas.1110740109

Willrodt C, David C, Cornelissen S, Bühler B, Julsing MK, Schmid A (2014) Engineering the productivity of recombinant Escherichia coli for limonene formation from glycerol in minimal media. Biotechnol J 9:1000-1012. https://doi.org/10.1002/biot.201400023

Wong J, de Rond T, D'Espaux L, van der Horst C, Dev I, Rios-Solis L, Kirby J, Scheller H, Keasling J (2018) High-titer production of lathyrane diterpenoids from sugar by engineered Saccharomyces cerevisiae. Metab Eng 45:142-148. https://doi.org/10.1016/J.YMBEN.2017.12.007

Wriessnegger T, Pichler H (2013) Yeast metabolic engineeringtargeting sterol metabolism and terpenoid formation. Prog Lipid Res 52:277-293. https://doi.org/10.1016/j.plipres.2013.03.001

Wriessnegger T, Augustin P, Engleder M, Leitner E, Müller M, Kaluzna I, Schürmann M, Mink D, Zellnig G, Schwab H, Pichler H (2014) Production of the sesquiterpenoid (+)-nootkatone by metabolic engineering of Pichia pastoris. Metab Eng 24C:18-29. https://doi.org/ 10.1016/j.ymben.2014.04.001

Wriessnegger T, Moser S, Emmerstorfer-Augustin A, Leitner E, Müller M, Kaluzna I, Schürmann M, Mink D, Pichler H (2016) Enhancing cytochrome P450-mediated conversions in P. pastoris through RAD52 over-expression and optimizing the cultivation conditions. Fungal Genet Biol 89:114-125. https://doi.org/10.1016/j.fgb.2016.02.004

Xie W, Ye L, Lv X, Xu H, Yu H (2015) Sequential control of biosynthetic pathways for balanced utilization of metabolic intermediates in Saccharomyces cerevisiae. Metab Eng 28:8-18. https://doi.org/10. 1016/j.ymben.2014.11.007

Yamada Y, Kuzuyama T, Komatsu M, Shin-Ya K, Omura S, Cane DE, Ikeda $\mathrm{H}$ (2015) Terpene synthases are widely distributed in bacteria. Proc Natl Acad Sci U S A 112:857-862. https://doi.org/10.1073/ pnas. 1422108112

Yang J, Nie Q, Ren M, Feng H, Jiang X, Zheng Y, Liu M, Zhang H, Xian M (2013) Metabolic engineering of Escherichia coli for the biosynthesis of alpha-pinene. Biotechnol Biofuels 6:60. https://doi.org/10. 1186/1754-6834-6-60

Yang X, Nambou K, Wei L, Hua Q (2016) Heterologous production of $\alpha$ farnesene in metabolically engineered strains of Yarrowia lipolytica. Bioresour Technol 216:1040-1048. https://doi.org/10.1016/j. biortech.2016.06.028

Ye L, Lv X, Yu H (2016) Engineering microbes for isoprene production. Metab Eng 38:125-138. https://doi.org/10.1016/j.ymben.2016.07.005

Yin H, Zhuang Y, Li E, Bi H, Zhou W, Liu T (2015) Heterologous biosynthesis of costunolide in Escherichia coli and yield improvement. Biotechnol Lett 37:1249-1255. https://doi.org/10.1007/ s10529-015-1784-6

Yoon S-H, Lee S-H, Das A, Ryu H-K, Jang H-J, Kim J-Y, Oh D-K, Keasling JD, Kim S-W (2009) Combinatorial expression of bacterial whole mevalonate pathway for the production of $\beta$-carotene in $E$. coli. $\mathrm{J}$ Biotechnol 140:218-226. https://doi.org/10.1016/j.jbiotec.2009.01.008

You S, Yin Q, Zhang J, Zhang C, Qi W, Gao L, Tao Z, Su R, He Z (2017) Utilization of biodiesel by-product as substrate for high-production of $\beta$-farnesene via relatively balanced mevalonate pathway in Escherichia coli. Bioresour Technol 243:228-236. https://doi.org/ 10.1016/J.BIORTECH.2017.06.058
Yuan J, Ching C-B (2015) Dynamic control of ERG9 expression for improved amorpha-4,11-diene production in Saccharomyces cerevisiae. Microb Cell Factories 14:38. https://doi.org/10.1186/ s12934-015-0220-x

Zada B, Wang C, Park J-B, Jeong S-H, Park J-E, Singh HB, Kim S-W (2018) Metabolic engineering of Escherichia coli for production of mixed isoprenoid alcohols and their derivatives. Biotechnol Biofuels 11:210. https://doi.org/10.1186/s13068-018-1210-0

Zebec Z, Wilkes J, Jervis AJ, Scrutton NS, Takano E, Breitling R (2016) Towards synthesis of monoterpenes and derivatives using synthetic biology. Curr Opin Chem Biol 34:37-43. https://doi.org/10.1016/j. cbpa.2016.06.002

Zhang H, Liu Q, Cao Y, Feng X, Zheng Y, Zou H, Liu H, Yang J, Xian M (2014) Microbial production of sabinene - a new terpene-based precursor of advanced biofuel. Microb Cell Factories 13:20. https://doi. org/10.1186/1475-2859-13-20

Zhang Y, Nielsen J, Liu Z (2017) Engineering yeast metabolism for production of terpenoids for use as perfume ingredients, pharmaceuticals and biofuels. FEMS Yeast Res 17:fox080. https://doi.org/10. 1093/femsyr/fox080

Zhang C, Chen X, Lindley ND, Too H-P (2018a) A “plug-n-play” modular metabolic system for the production of apocarotenoids. Biotechnol Bioeng 115:174-183. https://doi.org/10.1002/bit.26462

Zhang C, Liu J, Zhao F, Lu C, Zhao G-R, Lu W (2018b) Production of sesquiterpenoid zerumbone from metabolic engineered Saccharomyces cerevisiae. Metab Eng 49:28-35. https://doi.org/ 10.1016/J.YMBEN.2018.07.010

Zhao Y, Yang J, Qin B, Li Y, Sun Y, Su S, Xian M (2011) Biosynthesis of isoprene in Escherichia coli via methylerythritol phosphate (MEP) pathway. Appl Microbiol Biotechnol 90:1915-1922. https://doi.org/ 10.1007/s00253-011-3199-1

Zhao C, Gao X, Liu X, Wang Y, Yang S, Wang F, Ren Y (2016) Enhancing biosynthesis of a ginsenoside precursor by selfassembly of two key enzymes in Pichia pastoris. J Agric Food Chem 64:3380-3385. https://doi.org/10.1021/acs.jafc.6b00650

Zhao Y, Fan J, Wang C, Feng X, Li C (2018) Enhancing oleanolic acid production in engineered Saccharomyces cerevisiae. Bioresour Technol 257:339-343. https://doi.org/10.1016/J.BIORTECH.2018.02.096

Zhou YJ, Gao W, Rong Q, Jin G, Chu H, Liu W, Yang W, Zhu Z, Li G, Zhu G, Huang L, Zhao ZK (2012) Modular pathway engineering of diterpenoid synthases and the mevalonic acid pathway for miltiradiene production. J Am Chem Soc 134:3234-3241. https:// doi.org/10.1021/ja2114486

Zhou K, Zou R, Zhang C, Stephanopoulos G, Too H-P (2013) Optimization of amorphadiene synthesis in Bacillus subtilis via transcriptional, translational, and media modulation. Biotechnol Bioeng 110:2556-2561. https://doi.org/10.1002/bit.24900

Zhou J, Wang C, Yoon S-H, Jang H-J, Choi E-S, Kim S-W (2014) Engineering Escherichia coli for selective geraniol production with minimized endogenous dehydrogenation. J Biotechnol 169:42-50. https://doi.org/10.1016/J.JBIOTEC.2013.11.009

Zhou K, Qiao K, Edgar S, Stephanopoulos G (2015) Distributing a metabolic pathway among a microbial consortium enhances production of natural products. Nat Biotechnol 33:377-383. https://doi.org/10. 1038/nbt.3095

Zhou P, Xie W, Li A, Wang F, Yao Z, Bian Q, Zhu Y, Yu H, Ye L (2017) Alleviation of metabolic bottleneck by combinatorial engineering enhanced astaxanthin synthesis in Saccharomyces cerevisiae. Enzym Microb Technol 100:28-36. https://doi.org/10.1016/j. enzmictec.2017.02.006

Zwenger S, Basu C (2008) Plant terpenoids: applications and future potentials. Biotechnol Mol Biol Rev 3:1-7

Publisher's note Springer Nature remains neutral with regard to jurisdictional claims in published maps and institutional affiliations. 